\title{
Lysosomal Physiology
}

\author{
Haoxing $\mathrm{Xu}^{1}$ and Dejian Ren ${ }^{2}$ \\ ${ }^{1}$ Department of Molecular, Cellular, and Developmental Biology, University of Michigan, Ann \\ Arbor, Michigan 48109; haoxingx@umich.edu \\ ${ }^{2}$ Department of Biology, University of Pennsylvania, Philadelphia, Pennsylvania 19104; \\ dren@sas.upenn.edu
}

\begin{abstract}
Lysosomes are acidic compartments filled with more than 60 different types of hydrolases. They mediate the degradation of extracellular particles from endocytosis and of intracellular components from autophagy. The digested products are transported out of the lysosome via specific catabolite exporters or via vesicular membrane trafficking. Lysosomes also contain more than 50 membrane proteins and are equipped with the machinery to sense nutrient availability, which determines the distribution, number, size, and activity of lysosomes to control the specificity of cargo flux and timing (the initiation and termination) of degradation. Defects in degradation, export, or trafficking result in lysosomal dysfunction and lysosomal storage diseases (LSDs). Lysosomal channels and transporters mediate ion flux across perimeter membranes to regulate lysosomal ion homeostasis, membrane potential, catabolite export, membrane trafficking, and nutrient sensing. Dysregulation of lysosomal channels underlies the pathogenesis of many LSDs and possibly that of metabolic and common neurodegenerative diseases.
\end{abstract}

\section{Keywords}

TRPML1; TPC1; TPC2; mTOR; TFEB; lysosomal exocytosis; lysosomal storage disease

\section{INTRODUCTION: LYSOSOMES AS THE CENTER FOR NUTRIENT SENSING AND RECYCLING}

\footnotetext{
Lysosomes are the cell's degradation center and are primarily responsible for the breakdown of proteins, polysaccharides, and complex lipids into their respective building-block molecules: amino acids (AAs), monosaccharides, and free fatty acids $(1,2)$. Lysosomes are filled with more than 60 different types of hydrolases: lipases, proteases, and glycosidases for catabolic degradation (3). The products of degradation, lysosomal catabolites, are transported out of lysosomes via specific exporters in the limited membrane (4) or via vesicular membrane trafficking for energy homeostasis or reutilization in biosynthetic pathways (5).
}

\section{DISCLOSURE STATEMENT}

The authors are not aware of any affiliations, memberships, funding, or financial holdings that might be perceived as affecting the objectivity of this review. 
Lysosome-mediated catabolic degradation is an adaptive process regulated by nutrient status and cellular signaling (6). Lysosomes receive extracellular or cell surface cargos via endocytosis and receive intracellular components via autophagy (1). Whereas increases in the endocytic and autophagic fluxes stimulate lysosomal degradation $(2,3)$, accumulation of catabolites, e.g., AAs, in the lysosome terminates the degradation and autophagic flux $(7,8)$. To adapt to the changing cellular environment, lysosomes contain nutrient-sensing machinery that consists of mechanistic/mammalian target of rapamycin (mTOR), the master regulator of growth, and its associated proteins $(6,9,10)$. Nutrient starvation not only inhibits mTOR-mediated growth, but also increases autophagosome (AP) formation (7). Furthermore, it activates TFEB, the lysosomal biogenesis transcription factor, to facilitate lysosomal degradation by increasing lysosomal function (acidification and delivery of hydrolases) and trafficking (autophagosome -lysosome fusion) $(6,11)$.

Lysosomal adaptation to nutrient availability requires coordinated changes of multiple lysosomal parameters: distribution, number, and size $(7,11,12)$. In fed cells, lysosomes are heterogeneous in size (100--500 nm in diameter), morphology, and distribution (13). There are normally several hundred lysosomes in each mammalian cell. Upon nutrient starvation, lysosomal number is dramatically reduced to $<50$ per cell, and the size of the lysosome is increased to $500--1,500 \mathrm{~nm}$ as a result of membrane fusion $(7,14)$. In addition, lysosomes are redistributed to the perinuclear region, where AP-lysosome fusion primarily takes place (12). After prolonged starvation, the completion of autophagy triggers lysosomal reformation or biogenesis to restore lysosomal quantity (7).

Lysosomal ion channels and transporters play essential roles in regulating lysosomal homeostasis. First, lysosomal function requires the maintenance of the lumen homeostasis, especially ionic homeostasis and membrane potential $\left(\Delta \psi\right.$, defined as $V_{\text {cytosol }}-V_{\text {lumen }}$; $V_{\text {lumen }}$ is set to $0 \mathrm{mV}$ ) (3). For example, most lysosomal hydrolases require an acidic lumen to function (13). $\mathrm{H}^{+}$pumping for lysosomal acidification is also dependent on the lysosomal $\Delta \psi$, which is estimated to be $\sim-20$ to $-40 \mathrm{mV}$ (that is, 20 to $40 \mathrm{mV}$ more negative in the cytosol than in the lumen) $(15,16)$, as well as on the efflux of countercations and influx of counteranions $(16,17)$. Notably, due to the high density of various ion cotransporters and exchangers in the small-sized vesicles (18), an increase in the permeability of one ion may alter the concentration gradients of other ions, hence indirectly affecting ion homeostasis. Second, many catabolite exporters are sensitive to lysosomal $\Delta \psi$ (19--21). Third, lysosomal trafficking is regulated by $\mathrm{H}^{+}$homeostasis (22), $\Delta \psi(23)$, or $\mathrm{Ca}^{2+}$ (24). Although $\mathrm{H}^{+}$flux and $\Delta \psi$ may also indirectly affect lysosomal $\mathrm{Ca}^{2+}$ release (25), $\mathrm{Ca}^{2+}$ regulates most steps in lysosomal trafficking, including fusion of lysosomes with APs and late endosomes (LEs) (2, 26). LE-lysosome fusion mediates the delivery of most hydrolases to the lysosome (5).

Defective degradation, catabolite export, or trafficking leads to lysosomal dysfunction and lysosomal storage diseases (LSDs). Lysosomal channels directly or indirectly regulate all these processes. Indeed, impaired function of lysosomal channels underlies multiple LSDs $(22,24,27)$. 


\section{LYSOSOMAL ION HOMEOSTASIS}

Lysosomal degradation and the precise delivery of both hydrolases and cargos require the establishment of luminal ionic homeostasis, ionic gradients across the membrane, and $\Delta \psi$. In addition, lysosomal ion homeostasis is also required for the timely removal of the digested products and for the functionality of catabolite exporters. Below we discuss individual ions in the lumen. Given the size of the lysosome, however, the luminal concentrations of one ion must be viewed in the context of other ions and ion-dependent channels/transporters. In addition, lysosomal fusion events, especially the fusion of cytosol-derived, $\mathrm{K}^{+}$-loaded autophagosomes and $\mathrm{Na}^{+}$-loaded lysosomes (23), may rapidly change the ionic composition of the resulting organelle.

pH

The functions of most lysosomal hydrolases require an acidic $\left(\mathrm{pH}_{\text {lumen }} \sim 4.6\right)$ lumen; $\mathrm{V}$ ATPase establishes and maintains this $\mathrm{pH}(13)$. ClC transporters and $\mathrm{Na}^{+} / \mathrm{K}^{+}$channels/ transporters contribute to acidification by providing counterions $(17,22,50)$. In addition to assisting hydrolases, the established $100--1,000$-fold $\mathrm{H}^{+}$gradient is also important for lysosomal trafficking, $\Delta \psi$ generation, and content condensation during membrane fission (2, 18). For example, the V-ATPase inhibitor Bafilomycin-A1 is commonly used to block autophagosome -lysosome fusion (11). Furthermore, the $\mathrm{H}^{+}$gradient provides the driving force for many catabolite exporters (4). Finally, V-ATPase is essential for the lysosome to sense the luminal AA level (10).

\section{$\mathrm{Na}^{+} / \mathrm{K}^{+}$}

The luminal $\mathrm{Na}^{+}$and $\mathrm{K}^{+}$concentrations have been estimated only in a few cell types. The values range from $20--140 \mathrm{mM}$ for $\mathrm{Na}^{+}$(higher than $\left[\mathrm{Na}^{+}\right]_{\text {cytosol }}$ of $\sim 12 \mathrm{mM}$ ), and 2--50 mM for $\mathrm{K}^{+}$(lower than $\left[\mathrm{K}^{+}\right]_{\text {cytosol }}$ of $\left.\sim 150 \mathrm{mM}\right)(16,23)$. The large variation in the values presumably reflects ionic heterogeneity in lysosomes from different cells and the variation in the measurements. The mechanisms by which the ionic gradients between lysosomal lumen and the cytosol are established or maintained are largely unknown. Whereas endocytosis may provide $\mathrm{Na}^{+}$ions, endosomal $\mathrm{Na}^{+}$- or $\mathrm{K}^{+}$-coupled $\mathrm{H}^{+}$transporters may regulate luminal $\mathrm{Na}^{+} / \mathrm{K}^{+}$concentrations (18). Lysosomal membranes are permeable to both $\mathrm{Na}^{+}$and $\mathrm{K}^{+}$(see below). Because of the higher $\left[\mathrm{Na}^{+}\right]_{\text {lumen }}$ than $\left[\mathrm{Na}^{+}\right]_{\text {cytosol }}, \mathrm{Na}^{+}$efflux from lysosomal lumen into cytosol depolarizes the organelle $\Delta \psi$ toward the equilibrium (Nernst) potential of $\mathrm{Na}^{+}\left(\psi_{\mathrm{Na}},+57 \mathrm{mV}\right.$, assuming a $\left[\mathrm{Na}^{+}\right]_{\text {lumen }}$ of $100 \mathrm{mM}$ and a $\left[\mathrm{Na}^{+}\right]_{\text {cytosol }}$ of 12 $\mathrm{mM})$. Likewise, $\mathrm{K}^{+}$influx into the lysosome from cytosol hyperpolarizes $\Delta \psi$ toward $\psi_{\mathrm{K}}$ $\left(-54 \mathrm{mV}\right.$, assuming a $\left[\mathrm{K}^{+}\right]_{\text {lumen }}$ of $20 \mathrm{mM}$ and $\left[\mathrm{K}^{+}\right]_{\text {cytosol }}$ of $\left.150 \mathrm{mM}\right)$. The balance between the movements of $\mathrm{Na}^{+}$and $\mathrm{K}^{+}$across lysosomal membranes may set resting lysosomal $\Delta \psi$ $(18,54)$, which is determined by the membrane's permeability to each ion and the concentrations of the ions in the lumen and in the cytosol. $\Delta \psi$ is a critical determinant of the lysosomal acidification rate (17).

\section{$\mathrm{Ca}^{2+}$}

$\mathrm{Ca}^{2+}$ efflux from endosomes and lysosomes is thought to be important for signal transduction, organelle homeostasis, and organelle acidification $(2,18,25,58) .\left[\mathrm{Ca}^{2+}\right]_{l u m e n}$ 
is $\sim 0.5 \mathrm{mM}$, approximately 5,000 -fold higher than cytosolic $\left[\mathrm{Ca}^{2+}\right](\sim 100 \mathrm{nM})(46,57)$. The $\mathrm{Ca}^{2+}$ gradient is thought to be established by an unidentified $\mathrm{Ca}^{2+} / \mathrm{H}^{+}$exchanger or $\mathrm{Ca}^{2+}$ transporter (18). In cell-free vesicle fusion assays, LE-lysosome fusion is inhibited by the $\mathrm{Ca}^{2+}$ chelator BAPTA, but not by EGTA $(2,59)$. Although both BAPTA and EGTA have a high binding affinity for $\mathrm{Ca}^{2+}$, BAPTA binds to $\mathrm{Ca}^{2+}$ approximately 100 times faster than EGTA does (25). Therefore, such distinct BAPTA-versus-EGTA sensitivity suggests that the source of $\mathrm{Ca}^{2+}$ must be very close to the fusion spot (25). In other words, lysosomes most likely provide the $\mathrm{Ca}^{2+}$ required for lysosomal fusion (25, 59). Interestingly, preloading cells with membrane-permeable ester form of BAPTA (BAPTA-AM) blocks lysosomal exocytosis (35). Collectively, lysosomes may provide $\mathrm{Ca}^{2+}$ for membrane fusion between lysosomes and other compartments, including LEs and the plasma membrane.

The existence of multiple $\mathrm{Ca}^{2+}$ sensors may allow lysosomal $\mathrm{Ca}^{2+}$ release to regulate distinct steps of lysosomal trafficking. For lysosomal exocytosis, the $\mathrm{C} 2$ domain-containing synaptotagmin VII is likely the sensor (60). For LE-lysosome fusion, the candidate sensors include calmodulin (59) and ALG-2, a lysosome-targeted EF-hand protein (61). $\mathrm{Ca}^{2+}$-bound sensors may increase their association with preassembled SNARE complexes to facilitate lipid bilayer mixing (62).

\section{$\mathrm{Fe}^{2+}$ and $\mathrm{Zn}^{2+}$}

Lysosomal metals such as $\mathrm{Fe}^{3+}, \mathrm{Fe}^{2+}$, and $\mathrm{Zn}^{2+}$ ions are liberated via proteolysis of endocytosed or autophagocytosed metal-bound proteins (40). Lysosomes are the intracellular stores of $\mathrm{Fe}^{3+}, \mathrm{Fe}^{2+}, \mathrm{Zn}^{2+}$, and $\mathrm{Cu}^{2+}$ ions in micromolar concentrations (40, 41). Lysosomal export of $\mathrm{Fe}^{2+}$ and $\mathrm{Zn}^{2+}$ ions provides the cell with these trace metals as needed $(40,41)$. Whereas lysosomal $\mathrm{Fe}^{2+}$ is required for the Fenton reaction and for ROS production, as well as for the survival of lysosome-resident pathogens (40, 41), lysosomal $\mathrm{Zn}^{2+}$ may be required for the activity of hydrolases such as acid SMases (63). In addition, high lysosomal $\mathrm{Zn}^{2+}$ inhibits cathepsin activity (64). Whether heavy metal release regulates signal transduction or lysosomal trafficking remains unclear.

$\mathrm{Cl}^{-}$

$\left[\mathrm{Cl}^{-}\right]_{\text {lumen }}$, estimated to be higher than $80 \mathrm{mM}(22)$, may affect the function of catabolite exporters, as shown for many plasma membrane transporters (65). $\left[\mathrm{Cl}^{-}\right]$influx regulates endosomal $\mathrm{Ca}^{2+}$ release (66) and is required for lysosomal acidification by providing counterions for $\mathrm{H}^{+}$pumping $(17,22)$, as recently reviewed in this journal $(22,50)$.

\section{LYSOSOMAL FUNCTION}

\section{Lysosomal Trafficking}

Lysosomal function and trafficking (fusion and fission) are interconnected. Lysosomal trafficking supplies autophagic and endocytic substrates for degradation and hydrolases for lysosomal activation. In addition, lysosomal trafficking exports lipid catabolites and regulates consumption and biogenesis of lysosomes during lysosomal adaptation. 
Input: endocytosis and autophagy-The biomaterials destined for degradation are delivered to lysosomes through endocytic/phagocytic and autophagic pathways (Figure 1). Endocytosis or phagocytosis of extracellular or cell surface cargo begins with the fission of the plasma membrane to form endocytic vesicles, which then undergo a series of maturation processes to become early endosomes and then LEs (reviewed in Reference 1) (Figure 1). In the LEs, the destined-to-be-degraded endocytic cargos are sorted into intraluminal vesicles (1). Mature LEs, also termed multivesicular bodies, fuse with lysosomes to become endolysosome (EL) hybrids to mediate the bulk of the degradation (Figure 1). In addition, LE-lysosome fusion also delivers trans-Golgi network (TGN)-derived hydrolases for lysosomal function (5).

In a parallel pathway, worn-out intracellular organelles and protein aggregates are delivered to lysosomes through autophagy (Figure 1). Autophagosomes fuse directly, or indirectly through LEs, with lysosomes to form autolysosomes (ALs) $(28,29)$ in which the autophagic substrates are broken down (Figure 1). Although lysosomes receive cargo from both autophagic and endocytic pathways, there are no clear boundaries between ALs and EL hybrids (Figure 1) as autophagosomes may merge directly with LEs or even with early endosomes (30).

Output: reformation, retrograde trafficking, and exocytosis-There are at least three distinct output pathways in lysosomal trafficking. The best-understood example is exocytosis of lysosomal contents, i.e., lysosomal exocytosis, which is present in all cell types $(31,32)$. Upon stimulation, kinesin-associated lysosomes translocate from the perinuclear region to the plasma membrane along microtubules $(12,14,32,33)$. After docking, vesicle-associated membrane protein 7 (VAMP7), which is located on the lysosomal surface, forms a trans-SNARE complex with syntaxin-4 and SNAP23 on the plasma membrane $(31,34)$. Upon localized $\mathrm{Ca}^{2+}$ increase, lysosomes fuse directly with the plasma membrane (32), which can be monitored by measuring Lamp1 surface staining (Figure 1), by measuring lysosomal enzyme release, or by using an electrophysiology-based exocytosis assay $(31,35)$.

There are at least two membrane fission-based events in the lysosome. First, retrograde trafficking transports the free insoluble lipids out of late endosomes and lysosomes (LELs) to the TGN (Figure 1) for reutilization in biosynthetic pathways (5). Additionally, retrograde trafficking recycles the mannose-6-P receptor, which is required for TGN-to-LEL delivery of hydrolases (5). Second, lysosomal reformation from the ALs (7) or EL hybrids (2) is essential for lysosomal biogenesis and homeostasis (Figure 1). Upon mTOR reactivation after prolonged starvation, ALs undergo extensive tubulation (7). Lysosomes are then regenerated from these lysosomal tubules via a poorly-understood fission-based budding-off mechanism (7).

\section{Catabolite Exporters}

Insoluble lipid catabolites can be transported through vesicular trafficking. In contrast, soluble catabolites-for example, carbohydrates and AAs-are exported to the cytosol by specific transporters on the perimeter membrane $(4,36)$ (see Figure 2). 
Amino acid exporters-Only a few lysosomal amino acid transporters have been identified. Cystinosin/CTNS is a lysosomal $\mathrm{H}^{+}$-driven cysteine transporter (37). Mutations in CTNS cause abnormal accumulation of the amino acid cysteine (cystinosis) and secondary lysosomal storage (37). PQLC2/LAAT-1 is a lysosomal, $\mathrm{H}^{+}$-dependent arginine/ lysine exporter (21). Caenorhabditis elegans lacking LAAT- exhibit accumulation of arginine and lysine in enlarged lysosomes (38). Proton-assisted amino acid transporter 1 (PAT1)/SLC36A1, an intestinal AA transporter, is also localized in the lysosome and regulates AA export and sensing (39).

Sugar exporters-Sialin/SLC17A5, which is encoded by a gene that is mutated in sialic acid storage disorders, is a lysosomal $\mathrm{H}^{+}$-dependent exporter of sialic acids and acidic monosaccharides (4). Drosophila Spinster proteins are presumed to transport sugars that are produced upon lysosomal degradation of glycolipids, glycoproteins, or autophagocytosed glycogens (8). Cells lacking Spinster exhibit lysosomal dysfunction and storage (8).

Heavy metal exporters-Heavy metal ions are released into the lumen upon lysosomal degradation of autophagosed, heavy metal-containing proteins, such as cytochrome $c$ in mitochondria (40). During mitophagy or degradation of the iron storage protein ferritin, $\mathrm{Fe}^{3+}$ is dissociated and subsequently reduced to $\mathrm{Fe}^{2+}(40,41)$. DMT1 and NRAPM1 are lysosomal $\mathrm{Fe}^{2+}$ exporters in specialized cell types (41). The ubiquitously expressed Mucolipin TRP channel 1 (TRPML1), the principal $\mathrm{Ca}^{2+}$ channel in the lysosome, also conducts $\mathrm{Fe}^{2+}$ as well as $\mathrm{Zn}^{2+}$ and other heavy metal ions (42). Loss of TRPML1 results in lysosomal $\mathrm{Fe}^{2+}(40--42)$ and $\mathrm{Zn}^{2+}(43,44)$ overload.

Lipid exporters-Unlike other complex lipids in intraluminal vesicles, cholesterol is not degraded by lysosomal hydrolases but is sorted and presumably exported via the cholesterol transporter NPC1 (45). Mutations in NPC1 lead to lysosomal accumulation of cholesterol and sphingolipids, resulting in an LSD termed Niemann-Pick type C (NPC) $(45,46)$.

\section{Lysosomal Storage Diseases: Defects in Degradation, Export, or Trafficking}

Abnormal accumulation of lysosomal materials causes more than 50 rare inherited metabolic disorders in humans, collectively termed LSDs (47). Most LSDs are caused by mutations in lysosomal hydrolases (48). However, defective catabolite export and membrane trafficking may also lead to traffic jams and to secondary storage in the lysosome (49). Furthermore, primary accumulation of undigested, insoluble lipids may also slow down membrane trafficking and sorting, thereby affecting the delivery of lysosomal hydrolases $(2,49)$. Hence, problems in degradation, export, or trafficking negatively affect each other to cause lysosomal dysfunction and storage. Mutations in lysosomal channels and transporters lead to defective ion homeostasis, which in turn impairs lysosomal trafficking and degradation to result in lysosomal storage diseases $(22,46,50)$.

Progressive accumulation of undigested materials leads to build-up of enlarged ( $>1,000$ $\mathrm{nm}$ ), dysfunctional lysosomes (51). Increases in both vesicular content and osmolarity may cause vesicle enlargement. First, an increase in trafficking input or a decrease in trafficking output may also result in vesicle enlargement. Second, increased lysosomal osmolarity 
causes water influx to mechanically expand the vesicle (14). In normal physiology, a change in nutrient or cellular status results in a transient increase followed by a decrease in lysosomal size due to membrane fusion and subsequent fission events (7). Hence, large (>500-nm) Lamp1-positive compartments, i.e., ELs and ALs, are transient organelles or secondary lysosomes that, upon completion of lysosomal degradation, return to normal small-sized primary lysosomes via lysosomal reformation $(2,7)$. However, in LSDs, when lysosomal reformation or autophagosome-lysosome fusion is defective, EL/AL life span increases. Subsequently, secondary lysosomes, i.e., ELs/ALs, are filled with incompletely digested materials, which further enlarges ELs/ALs to $>1,000 \mathrm{~nm}$. This enlargement in turn causes further impairment in the equilibrium between input and output. Hence, the enlarged, dysfunctional lysosomes seen in LSDs are prolonged ELs/ALs. In essence, LSDs are caused by an escalating disequilibrium that results in endocytic and autophagic block or arrest (28).

With the presence of many degradation-defective enlarged ELs/ALs, the total number of lysosomes (estimated by the number of Lamp1-positive vesicles) may not be reduced in LSDs. However, the overall lysosomal function within a cell is compromised, leading to a deficiency of building-block precursors for biosynthetic pathways and to cellular starvation (48). In an attempt to compensate for the reduced degradative capacity, most cells in LSD maladaptively increase basal autophagy and the expression levels of housekeeping lysosomal proteins such as Lamp1 $(28,52)$. These compensatory changes may enable LSD cells to survive under normal conditions.

\section{Lysosomes as Energy and Nutrient Sensors}

In addition to the lysosome's long-recognized function as a recycling center for nutrient generation, lysosomal membranes were also recently found to directly monitor intracellular energy and extracellular nutrient status $(53,54)$. Lysosomes fulfill two central functions in energy and nutrient sensing. First, these organelles provide a physical platform for several of the most important nutrient-sensitive signaling molecules, such as mTOR and TFEB $(6,55)$. In response to changes in nutrient status, these proteins move onto the lysosomal surface, where they can be modified. Intriguingly, most of their known downstream targets are not lysosome-associated. For example, the targets of TFEB are in nuclei, and those of mTOR are largely cytosolic. That the surface of the lysosome is the focal point for nutrient sensors may be related to its relative mobility within cells. In addition, there may be advantages of stationing sensors around vacuoles that produce and export recycled nutrients. For example, mTOR senses AA contents both outside and within the organelle $(10,56)$.

Second, in a manner similar to that of plasma membranes that sense ATP with an ATPsensitive $\mathrm{K}^{+}$channel $\left(\mathrm{K}_{\mathrm{ATP}}\right)$, lysosomal membranes also sense [ATP] with ATP-sensitive $\mathrm{Na}^{+}$channels $(53,54)$. In addition, the $\mathrm{Na}^{+}$channels' ATP sensitivity is highly sensitive to extracellular nutrients, linking energy and nutrient status to lysosomal $\Delta \psi$.

\section{LYSOSOMAL ION CHANNELS AND CONDUCTANCES}

Ion channels and transporters in the lysosome provide the ionic environment necessary for degradation, pathways for export, and signals for lysosomal trafficking. Mutations of the few known lysosomal channel or transporter genes cause LSDs in humans or LSD-like 
phenotypes in mice $(22,67)$. The lysosome requires $\mathrm{H}^{+}$and $\mathrm{Fe}^{2+}$ channels/transporters to establish the ionic environment for proper oxidative and lytic function $\mathrm{As}^{+}$and $\mathrm{Ca}^{2+}$ ions are 1,000--5,000 times more concentrated in the lysosomal lumen than in the cytosol, the pathways for $\mathrm{H}^{+}$and $\mathrm{Ca}^{2+}$ flux, i.e., $\mathrm{Ca}^{2+}$ - and $\mathrm{H}^{+}$-permeant channels, must be tightly regulated.

Lysosomal ionic conductances have been studied by using ionic fluxes; single-channel recordings with purified proteins reconstituted in lipid bilayers; and, more recently, wholelysosomal recordings from artificially enlarged lysosomes $(18,23,42,68)$. Whole-lysosome recordings from enlarged vacuoles isolated from macrophages, neurons, fibroblasts, kidney cells, and cardiac myocytes have revealed native $\mathrm{K}^{+}, \mathrm{Na}^{+}, \mathrm{Ca}^{2+}, \mathrm{Cl}^{-}$, and $\mathrm{H}^{+}$conductances $(23,53,54,68)$ (Figure 2a).

\section{$\mathrm{K}^{+}$conductances}

In most vacuolin-enlarged lysosomes, a voltage-independent $\mathrm{K}^{+}$leak-like conductance has been recorded (53). The identity of this $\mathrm{K}^{+}$conductance is currently unknown. The $\mathrm{K}^{+}$ channel likely contributes to $\Delta \psi$, since alterations in $\left[\mathrm{K}^{+}\right]_{\text {cytosol }}$ affect $\Delta \psi$ (C. Cang \& D. Ren, unpublished

\section{$\mathrm{H}^{+}$conductances}

Consistent with the observation that V-ATPase inhibition quickly leads to lysosomal alkalization (57), there must exist a proton leak conductance; $\mathrm{H}^{+}$-dependent catabolite exporters are the leading candidates (8), but the electrogenic V-ATPase $\mathrm{H}^{+}$pump may also contribute (71).. In addition, there is also a depolarization-activated $\mathrm{H}^{+}$conductance (53). However, this conductance is insensitive to $\mathrm{Zn}^{2+}$ and activates rapidly (C. Cang \& D. Ren, unpublished), suggesting that it is not the voltage-activated $\mathrm{H}^{+}$channel (Hv1) $(72,73)$.

\section{$\mathrm{Cl}^{-}$conductances}

A depolarization-activated, fast-activating, outwardly rectifying $\mathrm{Cl}^{-}$conductance can be recorded from lysosomes (53). The $\mathrm{ClC}-7 \mathrm{H}^{+} / \mathrm{Cl}^{-}$exchanger is localized to lysosomes and is believed to permeate $\mathrm{Cl}^{-}$via a channel mechanism (74). ClC-7, coexpressed on the plasma membrane with Ostm1 in HEK293 cells, generates an outwardly rectifying $\mathrm{Cl}^{-}$conductance that activates much more slowly than the native lysosomal membrane-associated $\mathrm{Cl}^{-}$ conductance $(17,53,75)$. Further recordings from $\mathrm{ClC}-7 / \mathrm{Ostm} 1$-expressing lysosomes and from $\mathrm{ClC}-7 / \mathrm{Ostm} 1$ knockout lysosomes are required to determine whether $\mathrm{ClC}-7$ indeed encodes the native $\mathrm{Cl}^{-}$conductance.

\section{$\mathrm{Na}^{+}$conductances}

Like plasma membranes of excitable cells (76), the lysosome's relative permeability to $\mathrm{Na}^{+}$ and $\mathrm{K}^{+}\left(P_{\mathrm{Na}} / P_{\mathrm{K}}\right)$ changes markedly (by $\sim 30$-fold) depending on recording conditions (53). Both PI(3,5) $\mathrm{P}_{2}$-dependent $I_{\mathrm{Na}}(23)$ and $\mathrm{PI}(3,5) \mathrm{P}_{2}$-insensitive $I_{\mathrm{Na}}$ can be measured (X. Zhang $\&$ and $\mathrm{H}$. Xu, unpublished data). In the presence of $\mathrm{PI}(3,5) \mathrm{P}_{2}$, two major $\mathrm{Na}^{+}$conductances have been recorded $(23,53,54)$; in most mammalian lysosomes there is a voltageindependent $\mathrm{Na}^{+}$conductance, but in a subset of kidney and cardiac lysosomes, there is also 
a voltage-activated $\mathrm{Na}^{+}$conductance (lysoNa ). TPC 2 forms the voltage-independent $\mathrm{Na}^{+}$

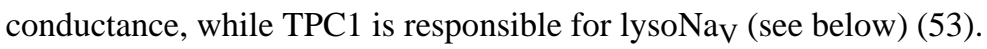

\section{$\mathrm{Ca}^{2+}$ CONDUTANCES}

$\mathrm{Ca}^{2+}$-permeant, nonselective cation channels have been recorded in the lysosomes of most mammalian cell types, including fibroblasts, macrophages, pancreatic cells, and skeletal muscle cells $(23,24,35,68)$. TRPMLs encode the primary lysosomal channel conducting calcium across lysosomal membranes (see below).

\section{$\mathrm{Fe}^{2+}$ and $\mathrm{Zn}^{2+}$ conductances}

Whereas overexpression of TRPMLs increases whole-lysosomal iron and zinc conductances (42), TRPML1-mutant organelles exhibited lysosomal $\mathrm{Fe}^{2+} / \mathrm{Fe}^{3+}$ and $\mathrm{Zn}^{2+}$ accumulation, suggesting that TRPMLs are channels that can conduct these metal ions from lysosome lumen to cytosol. $(41,78)$.

\section{Other conductances}

Endogenous conductances activated by sphingosine-1-phosphate and NAADP have been proposed, but not been directly measured under voltage-clamp (18). TPC overexpression in lysosomes increases NAADP-sensitive lysosomal calcium release. NAADP-activated cation channels have been recorded from TPC2 overexpressing lysosomes in several reports (80--82).

In summary, major ionic conductances have now been recorded from whole lysosomes (Figure 2). Because $I_{\mathrm{Na}}, I_{\mathrm{Ca}}, I_{\mathrm{Fe}}$, and $I_{\mathrm{Cl}}$ have been functionally characterized and molecularly identified, their physiological functions have been studied by using both in vitro and in vivo assays. Significantly, molecular and genetic studies have provided definitive evidence for the existence of these conductances, confirming their previously proposed cell biological functions. The $\mathrm{ClC}$ family of $\mathrm{H}^{+} / \mathrm{Cl}^{-}$exchangers likely responsible for lysosomal $\mathrm{Cl}^{-}$conductances were recently reviewed $(17,22)$. Below, we focus on the TRPML and TPC families.

\section{TRPML CHANNELS}

As the principal $\mathrm{Ca}^{2+}$ release channel in the lysosome, TRPML1 is a key regulator of most lysosomal trafficking processes $(26,83)$. Whereas human mutations of Trpmll cause type IV mucolipidosis (ML-IV) $(84,85)$ and inhibiting TRPML1 leads to several other LSDs (24), TFEB overexpression (86) can induce cellular clearance (of lysosomal storage materials) in most LSDs, except ML-IV (33), highlighting TRPML1's unique role in basic cell biology.

\section{An LEL-Localized TRP Channel}

The mucolipin subfamily of TRP channels (TRPML1-3), like other TRPs, consists of six putative transmembrane (TM)-spanning domains (S1-S6), with the $\mathrm{N}$ and $\mathrm{C}$ termini facing the cytosol (83). The channel pore of TRPML1 is formed by the pore-loop region between the S5 and S6 domains, which are presumed to form the channel gate (83). Whereas 
TRPML1 is ubiquitously expressed in every tissue and cell type, TRPML2 and TRPML3 are expressed only in special cell types $(83,87)$.

TRPML1-3 channels are predominantly (>75\%) localized on LEL membranes, but heterologously expressed TRPML1 proteins are also detected in the early endosomes and plasma membranes $(83,87)$. Two dileucine motifs located separately in the $\mathrm{N}$ - and $\mathrm{C}$ cytosolic tails are responsible for the LEL localization through a direct, AP1/3-dependent, TGN-LEL trafficking pathway and through an indirect, AP2-dependent, TGN-plasma membrane-LEL pathway (88--90). Mutations of both dileucine motifs result in significant TRPML1 surface expression (91).

\section{A Ca ${ }^{2+}$ and $\mathrm{Fe}^{2+} / \mathrm{Zn}^{2+}-$ Permeable Channel}

Due to the LEL localization of TRPML1, measuring the permeation and gating properties of the channel is difficult. However, the recent development of the whole-lysosome patchclamp technique $(42,66)$ has enabled the direct study of TRPML1 on artificially enlarged lysosomes (Figure $2 a$ ). These lysosomes are induced by vacuolin-1, a small-molecule chemical compound that selectively enlarges lysosomes (23, 92). TRPML1 is an inwardly rectifying (where inward indicates cations moving out of the lumen) permeable to $\mathrm{Ca}^{2+}$, $\mathrm{Fe}^{2+}, \mathrm{Zn}^{2+}, \mathrm{Na}^{+}$, and $\mathrm{K}^{+}$but impermeable to protons (42). Hence, upon activation, TRPML1 may mediate the release of $\mathrm{Ca}^{2+}, \mathrm{Fe}^{2+}$, and $\mathrm{Zn}^{2+}$ ions.

\section{$\mathrm{PI}(3,5) \mathrm{P}_{2}$ Activation}

Phosphoinositides are important regulators of membrane trafficking (93). Among them, $\mathrm{PI}(3) \mathrm{P}$ and $\mathrm{PI}(3,5) \mathrm{P}_{2}$ are localized on endosomes and lysosomes (94). Lysosomal trafficking is regulated by $\mathrm{PI}(3,5) \mathrm{P}_{2}$, whose synthesis requires the endosome-localized kinase PIKfyve in association with the FIG4 lipid phosphatase and scaffolding Vac14 proteins (94). $\mathrm{PI}(3,5) \mathrm{P}_{2}$ not only recruits a variety of cytoplasmic effector proteins to facilitate lysosomal trafficking (94), but also regulates the activity of lysosomal channels and transporters (94); such effects are similar to the effects of $\mathrm{PI}(4,5) \mathrm{P}_{2}$ on plasma membrane channels (95). Indeed, $\mathrm{PI}(3,5) \mathrm{P}_{2}$ activates whole-lysosome $I_{\text {TRPML1 }}$ in a physiologically relevant lownanomolar range (68). TRPML1 contains a cluster of positively charged AA residues that bind directly to $\mathrm{PI}(3,5) \mathrm{P}_{2}$ in in vitro protein/lipid-binding assays (68). Charge removal mutations abolished $\mathrm{PI}(3,5) \mathrm{P}_{2}$ activation and, importantly, eliminated the effect of TRPML1 on lysosomal trafficking (68).

A genetically encoded $\mathrm{PI}(3,5) \mathrm{P}_{2}$ indicator based on the $\mathrm{PI}(3,5) \mathrm{P}_{2}$-binding domain of TRPML1 was used to reveal that $\mathrm{PI}(3,5) \mathrm{P}_{2}$ levels increase transiently prior to fusion of two Lamp1-positive vesicles (96) and during phagocytic uptake of large particles (35). Therefore, under certain physiological conditions, $\mathrm{PI}(3,5) \mathrm{P}_{2}$ may play an instructive role in regulating lysosomal trafficking through TRPML1 activation.

How other trafficking cues regulate TRPML1 is not yet known. However, several synthetic small-molecule compounds were recently identified as $\mathrm{PI}(3,5) \mathrm{P}_{2}$-independent TRPML agonists $(24,97)$. Of them, mucolipin synthetic agonist 1 (ML-SA1) robustly activates 
TRPML1 at low-micromolar concentrations with a response comparable to that of $\mathrm{PI}(3,5) \mathrm{P}_{2}$ (24).

\section{$\mathrm{PI}(4,5) \mathrm{P}_{2}$ and Sphingomyelin Inhibition}

Two plasma membrane-localized lipids, $\mathrm{PI}(4,5) \mathrm{P}_{2}$ and sphingomyelin (SM), inhibit $I_{\text {TRPML1 }}(24,91)$. Conversely, $I_{\text {TRPML1 }}$ is potentiated by acid sphingomyelinases (aSMases) and phospholipase C (PLC) $(24,91)$. The inhibition may be a mechanism to prevent lysosomal TRPML1 from being active in nonnative compartments such as the plasma membrane. In addition, SMs accumulate in the lysosomes of aSMase-deficient NPA and NPB cells and cholesterol-accumulated NPC cells (48). Hence, TRPML1 inhibition may be an underlying pathogenic cause for certain LSDs.

\section{$\mathrm{Ca}^{2+-}$-Dependent Lysosomal Trafficking: Fusion-Based Input}

The permeation and gating properties of TRPML1 suggest that the channel function of TRPML1 is to release $\mathrm{Ca}^{2+}$ from the LEL lumen in response to various cellular cues (83, 98), such as an increase in lysosomal PI(3,5) $\mathrm{P}_{2}$. TRPML1 may regulate the LE maturation process involving LE-lysosome fusion, as the lysosomal delivery of endocytosed proteins, such as plasma membrane growth factor receptors, is delayed in $\operatorname{Trpml1}^{-1-}$ cells $(99,100)$. Likewise, in Trpml1 ${ }^{-/}$mouse neurons, LC3-positive autophagosomal puncta were elevated $(100,101)$, suggestive of increased AP formation and delayed AP-lysosome fusion (100, 101). Consistently, in Trpml $^{-/-}$fly neurons, AP-lysosome fusion was impaired (102). As increased AP formation is commonly observed in most LSDs (28), this process could also be a maladaptation to lysosomal dysfunction and basal TFEB activation in LSDs (6).

The fusion defects observed in Trpml1 $^{-/-}$cells, together with the $\mathrm{Ca}^{2+}$ dependence of LElysosome fusion observed in in vitro vesicle-mixing assays (2), suggest that TRPML1 may mediate lysosomal $\mathrm{Ca}^{2+}$ release to promote fusion. However, as most cellular assays do not directly measure vesicle fusion, these cellular defects may also be caused indirectly by chronic storage of lysosomal materials or defects in another cellular process, such as membrane fission. To maintain lysosomal homeostasis, lysosomal trafficking input and output must be coordinated. An increase in input must accompany a corresponding increase in output. Conversely, defects in output may also slow down the input process. Hence, the observed fusion defects are likely caused by the fission defects, and vice versa. To distinguish these possibilities, it may be necessary to perform super-resolution live-imaging to monitor fusion and fission events while acutely activating and inhibiting TRPML1's channel function.

\section{$\mathrm{Ca}^{2+}$-Dependent Lysosomal Trafficking: Fission-Based Output}

LEL-to-TGN retrograde trafficking is defective in ML-IV cells, as fluorescence-conjugated lactosylceramide, a lipid that is normally localized in the TGN at steady state, accumulates in LELs (103). This trafficking defect is also observed in other LSDs, including NPC (49), but can be rescued by increasing TRPML1 expression and activity (24), suggesting a direct role of TRPML1 in this specific trafficking step. On the basis of the observation that enlarged ELs accumulate in $\operatorname{Trpml}^{-/-}$C. elegans cells, it was proposed that lysosomal reformation (biogenesis) is defective in these cells (104). However, as other mechanisms 
may also account for lysosomal enlargement (see above), it is necessary to test whether acute activation and inhibition trigger and terminate lysosomal reformation, respectively.

\section{Lysosomal Exocytosis}

Multiple pieces of evidence suggest that TRPML1 regulates lysosomal exocytosis. First, HEK293 cells transfected with TRPML1 ${ }^{V 432 P}$ (a gain-of-function mutation) exhibit enhanced lysosomal exocytosis (105). In contrast, lysosomal exocytosis induced by TFEB overexpression requires TRPML1 (33), and ML-IV fibroblasts exhibit impaired ionomycininduced lysosomal exocytosis $(33,106)$. In primary macrophages, acute ML-SA1 treatment induced Lamp1 surface staining (see Figure $2 c$ ) and lysosomal enzyme release (35). In contrast, ML-SA1-induced lysosomal exocytosis was dramatically attenuated by TRPML1 knockout or BAPTA-AM (35).

TRPML1-mediated lysosomal exocytosis is required for the phagocytic uptake of large particles in macrophages (35). Macrophages engulf large cellular particles, such as apoptotic cells, by forming pseudopods (107). Pseudopod formation consumes large amounts of membrane (60) derived from lysosomal membranes (60). Trpml1 $^{-1-}$ macrophages exhibit uptake defects similar to those of synaptotagmin VII- or VAMP7-deficient macrophages (35), suggesting a role of TRPML1-mediated lysosomal exocytosis in particle uptake. Consistently, a lysosome-targeted, genetically encoded $\mathrm{Ca}^{2+}$ sensor, GCaMP3-TRPML1 (24), detects TRPML1-mediated $\mathrm{Ca}^{2+}$ release specifically at the site of particle uptake (35).

The repair of plasma membrane damage in skeletal muscle and other cell types requires a rapid $\mathrm{Ca}^{2+}$ increase to trigger the recruitment of intracellular vesicles that fuse with the plasma membrane and replace the disrupted membranes $(32,108)$. Both TRPML1 and lysosomal $\mathrm{Ca}^{2+}$ release are required for this process. Trpml1 knockout mice exhibit muscle repair defects and develop muscular dystrophy (108a).

\section{Metal Export}

Trpml1 $1^{-/-}$cells exhibit a cytosolic $\mathrm{Fe}^{2+}$ deficiency and concurrent lysosomal $\mathrm{Fe}^{2+}$ and $\mathrm{Zn}^{2+}$ overload, suggesting that TRPML1 is a lysosomal $\mathrm{Fe}^{2+}$ and $\mathrm{Zn}^{2+}$ exporter (42--44). ML-IV cells contain a large amount of lipofuscin in the lysosome, which can be explained by increased oxidative stress due to lysosomal $\mathrm{Fe}^{2+}$ overload (40, 41).

\section{Lysosomal Diseases}

More than 20 loss-of-function mutations in trpmll cause ML-IV, an LSD manifested by mental retardation, retinal degeneration, and constitutive achlorhydria $(27,84,85)$. As in ML-IV, trpmll knockout mice display neurological, gastric, and ophthalmological abnormalities, gradually developing hind-limb paralysis; mice typically die at 8--9 months (67). At the cellular level, dense membranous storage bodies are observed in most $\mathrm{trpml1}^{-/-}$ cells (67).

TRPML1's importance may also be extended to other LSDs, including NPA and NPC (24), in which TRPML1-mediated lysosomal $\mathrm{Ca}^{2+}$ release and lysosomal trafficking are partially blocked (24). Likewise, in PI(3,5) $\mathrm{P}_{2}$-deficient cells, TRPML1 activity is also reduced, which 
may cause lysosomal trafficking defects and storage (92). Furthermore, lysosomal trafficking is defective in many common neurodegenerative diseases, such as Alzheimer's, Parkinson's, and Huntington's diseases, suggesting a potential involvement of TRPML1. Collectively, TRPML1 channel dysregulation may be a primary pathogenic mechanism that results in secondary lysosomal storage in many lysosomal diseases.

\section{TWO-PORE CHANNELS (TPCs)}

TPC proteins form a unique branch of ion channels with a $2 \times 6 \mathrm{TM}$ structure, which is the transition state between the $6 \mathrm{TM}$ channels (such as voltage-gated $\mathrm{K}^{+}$channels $\left(\mathrm{K}_{\mathrm{V}} \mathrm{s}\right)$, TRPs, and sperm-specific $\mathrm{Ca}^{2+}$ channels (CatSpers)) and the 4x6 $\mathrm{TM}$ channels (voltage-gated $\mathrm{Ca}^{2+}$ channels $\left(\mathrm{Ca}_{V} \mathrm{~s}\right)$, voltage-gated $\mathrm{Na}^{+}$channels $(\mathrm{Na} V \mathrm{~s})$, and non-selective $\mathrm{Na}^{+}$-leak channel (NALCN)) (109). The overall sequences of TPCs are similar to those of Cavs and Navs $(110,111)$. There are three animal TPCs (TPC1-3). TPC3 is found only in some animals, such as cats, dogs, and chickens, but not in humans or mice $(110,112)$. TPC1 and TPC2 are widely expressed, with the highest TPC1 expression found in the heart and kidney. Heterologously expressed TPC proteins are localized in lysosomes (TPC1 and TPC2) and endosomes (TPC1) (114).

\section{TPC Selectivity}

Both TPC1 and TPC2 are highly selective for $\mathrm{Na}^{+}$. The apparent $P_{\mathrm{Na}} / P_{\mathrm{K}}$ estimated with whole-lysosomal recordings is $\sim 80$ for TPC1 (53) and $\sim 30$ for TPC2 (23). Whole-lysosomal TPC $\mathrm{Ca}^{2+}$ current is minimal or undetectable (23). Given the apparently low $\mathrm{Ca}^{2+}$ permeability, whether the fractional $\mathrm{Ca}^{2+}$ efflux directly from TPCs contributes to increases in cytosolic $\left[\mathrm{Ca}^{2+}\right]$ remains to be determined.

\section{TPC Regulation}

TPCs are the targets of a converging regulatory network with many physiological inputs from inside and outside the organelles. These inputs include luminal $\mathrm{H}^{+}$, lysosomal membrane potential, membrane $\mathrm{PI}(3,5) \mathrm{P} 2$, lysosome-attached protein kinases, $\mathrm{Mg}^{2+}$ ions, cytosolic ATP and extracellular nutrients such as amino acids.

Membrane voltage-When recorded with symmetric ion concentrations in the bath and pipette, TPC 2 has a largely linear $I-\Psi$ relationship, and the currents rise and fall instantaneously upon voltage changes, without apparent activation and deactivation $(23,53$, 54). These properties of TPC 2 are similar to those of the native $\mathrm{Na}^{+}$channel recorded from lysosomes. TPC2-mediated lysosomal $\mathrm{Na}^{+}$conductance is controlled by the availability of organellar $\mathrm{PI}(3,5) \mathrm{P}_{2}(23)$, cytosolic ATP, and extracellular nutrients (116), which together presumably regulate lysosomal $\Delta \psi$.

TPC1 is voltage activated (53). At $\mathrm{pH}_{\text {lumen }} 4.6$, the channel opens at $\Delta \psi>0 \mathrm{mV}$. Compared with the voltage dependences of the strongly voltage-dependent $\mathrm{K}_{\mathrm{V}} \mathrm{s}$, TPC1's voltage dependence of activation is much weaker (with a slope factor of $\sim 20--50 \mathrm{mV}$ versus a few millivolts in $\mathrm{K}_{\mathrm{V}} \mathrm{s}$ ) (53). Like $\mathrm{K}_{\mathrm{V}} \mathrm{s}$, TPC1 has $\mathrm{S} 1-\mathrm{S} 4$ voltage-sensing domains (VSDs) whose $\mathrm{S} 4 \mathrm{~s}$ contain charged residues (K/R) in an every-third-residue fashion. Mutating several of the charged residues that are on TPC 1 but not on TPC 2 rendered TPC1 largely voltage 
independent, suggesting that the organelles also use the S1-S4 VSDs to sense voltage changes.

Unlike any other voltage-gated $\mathrm{Na}^{+}$channel currently known, TPC1 activates slowly ( $\tau \sim$ $100 \mathrm{~ms}$ ) (53). At a holding potential of $-70 \mathrm{mV}$, the channel did not inactivate at any of the depolarizing voltages (53). Upon $\mathrm{PI}(3,5) \mathrm{P}_{2}$ activation, $I_{\mathrm{TPC} 1}$ at negative voltages exhibited voltage-dependent fast decay presumed to be due to channel inactivation (23). Because TPC1-encoded $\mathrm{Na}_{\mathrm{V}}$ makes the organelle excitable (see below), the lack of inactivation and the slow deactivation presumably help sustain depolarization. The slow activation may act similarly to a low-pass filter in preventing noise-induced depolarization, which is especially useful for organelles with high input resistance.

Luminal $\mathrm{pH}-\mathrm{TPC} 1$ is highly sensitive to $\mathrm{pH}_{\text {lumen }}$. A one-unit $\mathrm{pH}$ increase from 4.6 to 5.6 shifts TPC1's conductance $(G)-\Psi$ relationship toward hyperpolarization by $62 \mathrm{mV}$ (53). For comparison, a pure- $\mathrm{H}^{+}$electrode has a voltage response of $61.5 \mathrm{mV} / \mathrm{pH}$ unit at $37^{\circ} \mathrm{C}$. How $\mathrm{pH}$ so markedly affects the channel's voltage sensing and/or coupling to channel opening is not known. Because of the channel's high pH sensitivity, a pH increase in the lysosome can also increase the basal $\mathrm{Na}^{+}$conductance, which depolarizes the lysosomal membranes to allow for easier $\mathrm{H}^{+}$entry into the lumen. Thus, a TPC1-mediated $\mathrm{pH}-\Psi$ feedback loop may help maintain the stability of lysosomal pH. Similarly, the high $\mathrm{pH}$ sensitivity of TPC1's activation threshold may help set the resting $\Delta \psi$ during maturation of the organelles, a process associated with large $\mathrm{pH}$ changes from $\sim 6.0$ to $\sim 4.5$ (18).

$\mathbf{P I}(\mathbf{3}, \mathbf{5}) \mathbf{P}_{\mathbf{2}}$ - In vacuolin-1-enlarged lysosomes expressing recombinant TPCs, large currents can be recorded in the presence of exogenously applied di-C8-PI(3,5) $\mathrm{P}_{2}\left[\mathrm{EC}_{50}\right.$ of $\sim 400 \mathrm{nM}$ for TPC2 (23) and $\sim 100 \mathrm{nM}$ for TPC1 (53)]. In addition, native $I_{\mathrm{TPC} 1}$ recorded from enlarged cardiac myocyte lysosomes has similar $\mathrm{PI}(3,5) \mathrm{P}_{2}$ sensitivity, suggesting that lipid sensitivity does not result from channel overexpression (53). TPC's $\mathrm{PI}(3,5) \mathrm{P}_{2}$ sensitivity is specific, as $\mathrm{PI}(4,5) \mathrm{P}_{2}$ and $\mathrm{PI}(3,4) \mathrm{P}_{2}$ do not activate TPC1 or TPC2 $(23,53)$. Unlike the mammalian TPCs, plant TPC1 is a voltage- and $\mathrm{Ca}^{2+}$-sensitive, nonselective cation channel but is $\mathrm{PI}(3,5) \mathrm{P}_{2}$ insensitive (118). In mammalian cells, nutrient availability regulates lysosomal $\mathrm{PI}(3,5) \mathrm{P}_{2}$ levels (119). Whether $\mathrm{PI}(3,5) \mathrm{P}_{2}$ regulation of TPCs plays a role in lysosomal nutrient sensing remains to be determined.

$\mathrm{Mg}^{2+}$-At a physiological concentration of $\sim 0.5 \mathrm{mM}, \mathrm{Mg}^{2+}$ suppresses $\sim 50 \%$ of outward $I_{\mathrm{TPC} 2}$, presumably through a pore-blockade mechanism (82). The suppression of inward $I_{\mathrm{TPC}}$ (the direction under physiological conditions) by $\mathrm{Mg}^{2+}$ is much weaker. Whether a change in $\left[\mathrm{Mg}^{2+}\right]$ regulates TPC's in vivo function requires further studies.

Cytosolic ATP-Lysosomal ATP-sensitive $\mathrm{Na}^{+}$channels (lysoNa $\mathrm{ATP}_{\mathrm{P}}$ ) have been recorded from several cell types, including macrophages, fibroblasts, hepatocytes, neurons, kidney cells, and cardiac myocytes $(53,54)$. In lysosomes isolated from nutrient-replete HEK293 cells transfected with TPC1 or TPC2, both $I_{\mathrm{TPC} 1}$ and $I_{\mathrm{TPC} 2}$ are inhibited by ATP at an $\mathrm{IC}_{50}$ of $\sim 0.1 \mathrm{mM}$ (54). In addition, lysoNa $\mathrm{ATP}_{\mathrm{A}}$ is absent in $t p c$ knockout lysosomes (54). These findings suggest that TPCs are the major ATP-sensitive channels in the organelle. 
How ATP inhibits TPCs is not well understood. ATP binds and inhibits $\mathrm{K}_{\text {ATP }}(120)$. Similar direct inhibition does not explain TPC's ATP sensitivity, as the inhibition is slow ( 1 min) and requires protein kinases $(54,82)$. Because ATP sensitivity is preserved in a patch-clamp recording configuration with isolated lysosomes, the kinases must be tightly tethered to the lysosomal surfaces. The best-studied lysosome-attached kinase is mTOR (121). Indeed, inhibiting mTOR with either small-molecule chemicals or shRNA depletion disrupts TPC's ATP sensitivity. In contrast, AMPK, a highly ATP/AMP-sensitive kinase, is not required for the channel's ATP sensitivity (54). Several other kinases, including p38 and JNK, also inhibit $I_{\mathrm{TPC} 2}(82)$.

The ATP sensitivity of many protein kinases is at approximately micromolar range, too low to be a meaningful sensor for physiological [ATP], which is in the $1 \mathrm{mM}$ range. Under certain conditions, mTOR's ATP sensitivity is within the millimolar range (122), making the kinase a feasible ATP sensor for the channel. TPC proteins associate with mTOR in coimmunoprecipitation assays. In addition, mTOR's kinase activity is required for the channel's ATP activity, as a kinase-dead mTOR mutant is unable to support this sensitivity (54). However, there is no evidence that TPC protein phosphorylation by mTOR is responsible for the ATP inhibition. The direct kinase target important for TPC may be an asyet-unidentified TPC-associated subunit.

Extracellular nutrients-TPCs are also highly sensitive to the availability of extracellular nutrients. Glucose can directly control $I_{\text {TPC }}$ through ATP generation by glycolysis. In contrast, extracellular AAs indirectly regulate $I_{\text {TPC }}$ by controlling TPC's ATP sensitivity and $\mathrm{PI}(3,5) \mathrm{P}_{2}$ availability. On lysosomes isolated from cells starved for AAs for 60 min, TPC is little inhibited by ATP, and such ATP sensitivity is quickly restored upon AA refeeding (54). Thus, either [ATP] drop or insufficiency in extracellular AAs leads to TPC opening. Whether TPCs are also sensitive to other nutrients such as circulating fatty acids remains to be determined.

Extracellular AAs control TPC's ATP sensitivity through an mTOR-based mechanism (54). In AA-fed cells, mTORC1 (mTOR complex 1) is recruited by the Ragulator-Rag GTPase complex to the lysosomal surface, where the kinase is activated by Rheb (a Ras-related GTP-binding protein) $(56,123)$. Upon AA starvation, Rag GTPases loosen the mTORlysosome association and recruit TSC2 (tuberous sclerosis complex 2, a GTPase-activating protein) onto the lysosome to inactivate Rheb (55). Transfecting RagB GTP a GTP-bound Rag mutant that keeps mTOR on the lysosome, renders TPC inhibited by ATP even during cell starvation. Conversely, $\operatorname{RagB}^{\mathrm{GDP}}$, a GDP-bound Rag mutant that prevents mTOR being recruited to the lysosomal surfaces, makes the channel insensitive to ATP in AA-fed cells. Rheb and TSC2 also receive inputs from many other physiological and pathophysiological stimuli such as growth factor stimulation, inflammation, and hypoxia. The mTOR network is extensively linked to many signaling pathways and diseases such as diabetes, cancer, neurodegeneration, and autism (121). It will be interesting to test whether these pathways and diseases also regulate TPCs to influence lysosomal function, which is implicated in some pathological conditions. 
NAADP-TPCs were first functionally characterized as candidates for NAADP-activated $\mathrm{Ca}^{2+}$-release channels (114). TPC proteins reconstituted in lipid bilayers led to NAADPactivated $\mathrm{Ca}^{2+}$ - or $\mathrm{Ba}^{2+}$-permeable single-channel activities (124). Under whole-organelle recordings with TPC2-expressing LELs, NAADP also activated a $\mathrm{Ca}^{2+}$ current in one study (80) and a small $\mathrm{Na}^{+}$current ( $4 \%$ of the maximum in the absence of $\mathrm{Mg}^{2+}$ ) in another (82). In several other studies with physiological concentration of $\mathrm{Mg}^{2+}$ in the whole-lysosomal recording solution, no NAADP activation was observed $(23,53,54)$. Reconciling the apparent discrepancies in the channel activation and ion selectivity is difficult at present (125). Photoaffinity labeling suggests that NAADP binds to proteins much smaller than TPCs (126). Therefore, a yet-to-be-isolated subunit harboring the NAADP-binding site may be required for robust channel activation.

\section{TPC's Cellular and Organismal Functions}

TPCs' in vivo functions have been studied using knockout mice. TPCs are not required for the animals' viability under lab conditions as mice with both $t p c 1$ and $t p c 2$ knocked out are fertile and appear normal. The channels' function becomes more pronounced under stress conditions such as decreased availability of ATP and nutrients. Activation of TPCs helps to set lysosomal membrane potential, to ensure lumen $\mathrm{pH}$ stability, to facilitate amino acid efflux from the lysosome, to provide circulating amino acids for energy generation and to enhance animal's physical endurance during food restriction.

Membrane potential regulation-Due to TPCs' dominant contribution to $\mathrm{Na}^{+}$ conductances, a major cellular function of the channel may be to set $\Psi$, which in turn controls many other responses. Conditions that lead to TPC opening drastically increase $P_{\mathrm{Na}} / P_{\mathrm{K}}$ by $\sim 30$-fold and depolarize $\Psi$ by $\sim 70 \mathrm{mV}$ (53). In addition, as TPCs are the major lysosomal ATP-sensitive ion channels and others, such as the $\mathrm{K}^{+}$channel, appear to be ATP insensitive (53; C. Cang \& D. Ren, unpublished), decreases in $[\mathrm{ATP}]_{\text {cyt }}$ lead to organelle depolarization in wild-type lysosomes, but not in tpc knockout lysosomes (54).

Organelle excitability_LELs are electrically excitable. In a subset of LELs, a brief (200$\mathrm{ms}$ ) depolarization stimulus leads to a TPC1-dependent, long-lasting depolarization spike, resulting in $\Delta \psi$ bistability. The function of the apparent organelle bistability is totally unknown. On the plasma membrane, $\mathrm{Na}_{\mathrm{V}}$-mediated depolarization activates $\mathrm{Ca}^{2+}$ influx through $\mathrm{Ca}_{V}$ s. Whether voltage-activated $\mathrm{Ca}^{2+}$ channels are also functional on LEL membranes is unknown. Similarly, it is not clear whether there is a feedback loop between $\Psi$ and chemical messages to generate an oscillating signaling network, similar to the excitable electrical-chemical behavior of mitochondria (128).

Lysosomal $\mathrm{pH}$-For efficient acidification of lysosomes by the V-ATPase, $\mathrm{Cl}^{-}, \mathrm{Na}^{+}$, and $\mathrm{K}^{+}$are believed to provide counterions by anion influx and/or cation efflux $(16,17)$. In nutrient-replete $t p c$ knockout macrophages, lysosomes are only slightly alkalinized by $\sim 0.1$ $\mathrm{pH}$ units compared with the wild-type $\mathrm{pH}$. That TPC mutation does not have a major impact on $\mathrm{pH}$ is consistent with the idea that TPC activity is minimal at resting in nutrient-replete cells. The large basal $\mathrm{K}^{+}$conductance presumably provides the countercation (53). Upon nutrient starvation, however, $t p c$ knockout lysosomes are markedly alkalinized by $\sim 0.6 \mathrm{pH}$ 
units, whereas while wild-type $\mathrm{pH}$ is relatively stable (54). The contribution of TPCs to $\mathrm{pH}$ stability is due to the fact that channel opening leads to organelle depolarization (a less positive luminal voltage), a condition more favorable for the V-ATPase $\mathrm{H}^{+}$pump.

Amino acid efflux-A somewhat unexpected role of TPC is in lysosomal AA efflux. In lysosomes loaded with radiolabeled lysine, the AA efflux rate in the knockout is significantly lower than that in the wild type when [ATP] is lowered to $0.1 \mathrm{mM}$ (54). Conversely, overexpressing TPC increases the efflux rate (C. Cang \& D. Ren, unpublished). How TPC opening speeds up the efflux rate is unknown and cannot be explained simply by membrane depolarization, which actually decreases the efflux driving force for the positively charged AA. Some of the transporters may also be regulated by $\Delta \psi(19)$, which is controlled by TPC-mediated $\mathrm{Na}^{+}$conductances.

Other cellular functions-Overexpression, knockdown, or knockout experiments have revealed that TPCs are important for autophagy, neuronal differentiation, osteoclastogenesis, T cell killing, receptor-stimulated smooth muscle contraction, cholesterol processing in hepatocytes and the acrosome reaction in sperm (129--134).

Function at the whole-organism level-No severe human disease has been found to be caused by TPC mutations. TPC 2 variation is associated with pigmentation determination, suggesting that TPCs may function in the lysosome-related organelle melanosome (135). Under normal housing conditions, well-fed $t p c 1 / t p c 2$ double-knockout mice with a mixed background are viable, fertile, and without obvious gross abnormality. Under fasting conditions, however, the mutant mice have severely reduced physical endurance. During fasting, the levels of several AAs in the circulation increase in the wild type, an adaptive process presumably involving the generation of AAs and their export by lysosomes. Such an increase is absent in the knockout mice. These findings suggest that under normal conditions, when animals are supplied with sufficient nutrients, TPC's role is less significant because ATP suppresses the channel. Under environmental and cellular stress, TPC activity increases, and the channel's function becomes apparent. Intriguingly, plant TPC1's functional importance becomes apparent only when the organism is under stress challenge, such as exposure to excessive salt and wounding $(136,137)$. Hence TPCs may have been evolved to expand adaptive responses to stress.

\section{TARGETING LYSOSOMAL CHANNELS TO TREAT LYSOSOMAL STORAGE DISEASES?}

Mutations in hydrolases or exporters cause lysosomal storage, which in turn affect lysosomal degradation and trafficking to cause secondary storage, resulting in a vicious cycle. As a central regulator of lysosomal trafficking, deinhibition of TRPML1 may break this vicious cycle. Indeed, TRPML1 overexpression and small-molecule TRPML1 agonists can increase cholesterol clearance in NPC cells (24). Additionally, TRPML1 activation may boost phagocytic clearance of apoptotic debris in the brain $(35,138)$. Hence, manipulating the expression and activity of TRPML1 and other lysosomal channels may provide an exciting opportunity to clear lysosomal storage in NPC cells. As lysosomal trafficking 
defects are commonly seen in LSDs (49), this approach could potentially provide a novel therapeutic approach for many other LSDs.

If increasing TRPML1 expression or activity promotes cellular clearance, cellular conditions or manipulations that boost TRPML1 expression or activity may also enhance lysosomal function. TFEB is a master regulator of lysosomal biogenesis and autophagy $(6,9,86)$. When autophagy is triggered or when lysosomes are under stress conditions, TFEB proteins translocate from the cytoplasm to the nucleus, thereby inducing the expression of hundreds of autophagy- and lysosome-related genes $(9,86)$. In MSD and MPS-IIIA, two glycosaminoglycan (GAG)-storage LSDs, TFEB overexpression was sufficient to reduce lysosomal GAG accumulation (33). Similarly, cellular clearance was observed in the mouse models of Batten, Neuronal ceroid lipofuscinoses (NCL), and Pompe's diseases $(33,139)$. Strikingly, the beneficial effects of TFEB on various LSDs depend on TRPML1 and lysosomal exocytosis $(33,139)$. Because TRPML1 is upregulated by TFEB overexpression $(33,140)$, the TFEB-TRPML1 interaction may play a pivotal role in promoting lysosomal exocytosis for cellular clearance.

\section{CONCLUSION}

The lysosome is a highly dynamic organelle that integrates multiple metabolic pathways to maintain cellular homeostasis and regulate basic cellular functions, including cell growth and death. Lysosomal ion channels and transporters play a central role in lysosomal degradation, trafficking, catabolite export, nutrient sensing, and homeostasis. However, the molecular identities of most lysosomal channels are unknown. In addition, the regulation of lysosomal channels by environment factors and cellular cues is largely unexplored. Highresolution live-cell imaging will be necessary to detect lysosomal dynamics under various physiological conditions and upon acute manipulation of the activity of lysosomal channels. We hope that enhancing lysosomal trafficking may alleviate the pathological symptoms in most LSDs regardless of the primary deficiency. Whether lysosomal channels can be common targets for the treatment of many LSDs awaits deeper understanding.

\section{Supplementary Material}

Refer to Web version on PubMed Central for supplementary material.

\section{ACKNOWLEDGMENTS}

We apologize to colleagues whose works are not cited due to space limitations. The works in the authors' laboratories are supported by NIH grants (NS062792, MH096595, and AR060837 to H.X. and NS055293 and NS074257 to D.R.). We appreciate the encouragement and helpful comments of members of the Xu and Ren laboratories.

\section{LITERATURE CITED}

1. Huotari J, Helenius A. Endosome maturation. EMBO J. 2011; 30:3481-500. [PubMed: 21878991]

2. Luzio JP, Pryor PR, Bright NA. Lysosomes: fusion and function. Nat. Rev. Mol. Cell Biol. 2007; 8:622-32. 
3. Kolter T, Sandhoff K. Principles of lysosomal membrane digestion: stimulation of sphingolipid degradation by sphingolipid activator proteins and anionic lysosomal lipids. Annu. Rev. Cell Dev. Biol. 2005; 21:81-103.

4. Ruivo R, Anne C, Sagne C, Gasnier B. Molecular and cellular basis of lysosomal transmembrane protein dysfunction. Biochim. Biophys. Acta. 2009; 1793:636-49. [PubMed: 19146888]

5. Saftig P, Klumperman J. Lysosome biogenesis and lysosomal membrane proteins: Trafficking meets function. Nat. Rev. Mol. Cell Biol. 2009; 10:623-35.

6. Settembre C, Fraldi A, Medina DL, Ballabio A. Signals from the lysosome: a control centre for cellular clearance and energy metabolism. Nat. Rev. Mol. Cell Biol. 2013; 14:283-96. [PubMed: 23609508]

7. Yu L, McPhee CK, Zheng L, Mardones GA, Rong Y, et al. Termination of autophagy and reformation of lysosomes regulated by mTOR. Nature. 2010; 465:942-46. [PubMed: 20526321]

8. Rong Y, McPhee CK, Deng S, Huang L, Chen L, et al. Spinster is required for autophagic lysosome reformation and mTOR reactivation following starvation. Proc. Natl. Acad. Sci. USA. 2011; 108:7826-31. [PubMed: 21518918]

9. Settembre C, Di Malta C, Polito VA, Garcia Arencibia M, Vetrini F, et al. TFEB links autophagy to lysosomal biogenesis. Science. 2011; 332:1429-33. [PubMed: 21617040]

10. Zoncu R, Bar-Peled L, Efeyan A, Wang S, Sancak Y, Sabatini DM. mTORC1 senses lysosomal amino acids through an inside-out mechanism that requires the vacuolar $\mathrm{H}^{+}$-ATPase. Science. 2011; 334:678-83. [PubMed: 22053050]

11. Zhou J, Tan SH, Nicolas V, Bauvy C, Yang ND, et al. Activation of lysosomal function in the course of autophagy via mTORC1 suppression and autophagosome-lysosome fusion. Cell Res. 2013; 23:508-23. [PubMed: 23337583]

12. Korolchuk VI, Saiki S, Lichtenberg M, Siddiqi FH, Roberts EA, et al. Lysosomal positioning coordinates cellular nutrient responses. Nat. Cell Biol. 2011; 13:453-60. [PubMed: 21394080]

13. Mellman I. Organelles observed: lysosomes. Science. 1989; 244:853-54. [PubMed: 17802262]

14. Bandyopadhyay D, Cyphersmith A, Zapata JA, Kim YJ, Payne CK. Lysosome transport as a function of lysosome diameter. PLOS ONE. 2014; 9:e86847. [PubMed: 24497985]

15. Ohkuma S, Moriyama Y, Takano T. Electrogenic nature of lysosomal proton pump as revealed with a cyanine dye. J. Biochem. 1983; 94:1935-43. [PubMed: 6608518]

16. Steinberg BE, Huynh KK, Brodovitch A, Jabs S, Stauber T, et al. A cation counterflux supports lysosomal acidification. J. Cell Biol. 2010; 189:1171-86. [PubMed: 20566682]

17. Ishida Y, Nayak S, Mindell JA, Grabe M. A model of lysosomal pH regulation. J. Gen. Physiol. 2013; 141:705-20. [PubMed: 23712550]

18. Morgan AJ, Platt FM, Lloyd-Evans E, Galione A. Molecular mechanisms of endolysosomal $\mathrm{Ca}^{2+}$ signalling in health and disease. Biochem. J. 2011; 439:349-74. [PubMed: 21992097]

19. Pisoni RL, Thoene JG. The transport systems of mammalian lysosomes. Biochim. Biophys. Acta. 1991; 1071:351-73. [PubMed: 1751541]

20. Dickson EJ, Duman JG, Moody MW, Chen L, Hille B. Orai-STIM-mediated $\mathrm{Ca}^{2+}$ release from secretory granules revealed by a targeted $\mathrm{Ca}^{2+}$ and $\mathrm{pH}$ probe. Proc. Natl. Acad. Sci. USA. 2012; 109:E3539-48. [PubMed: 23184982]

21. Jezegou A, Llinares E, Anne C, Kieffer-Jaquinod S, O'Regan S, et al. Heptahelical protein PQLC2 is a lysosomal cationic amino acid exporter underlying the action of cysteamine in cystinosis therapy. Proc. Natl. Acad. Sci. USA. 2012; 109:E3434-43. [PubMed: 23169667]

22. Stauber T, Jentsch TJ. Chloride in vesicular trafficking and function. Annu. Rev. Physiol. 2013; 75:453-77. [PubMed: 23092411]

23. Wang X, Zhang X, Dong XP, Samie M, Li X, et al. TPC proteins are phosphoinositide-activated sodium-selective ion channels in endosomes and lysosomes. Cell. 2012; 151:372-83. [PubMed: 23063126]

24. Shen D, Wang X, Li X, Zhang X, Yao Z, et al. Lipid storage disorders block lysosomal trafficking by inhibiting a TRP channel and lysosomal calcium release. Nat. Commun. 2012; 3:731. [PubMed: 22415822] 
25. Luzio JP, Bright NA, Pryor PR. The role of calcium and other ions in sorting and delivery in the late endocytic pathway. Biochem. Soc. Trans. 2007; 35:1088-91. [PubMed: 17956286]

26. Li X, Garrity AG, Xu H. Regulation of membrane trafficking by signalling on endosomal and lysosomal membranes. J. Physiol. 2013; 591:4389-401. [PubMed: 23878375]

27. Slaugenhaupt SA. The molecular basis of mucolipidosis type IV. Curr. Mol. Med. 2002; 2:445-50. [PubMed: 12125810]

28. Lieberman AP, Puertollano R, Raben N, Slaugenhaupt S, Walkley SU, Ballabio A. Autophagy in lysosomal storage disorders. Autophagy. 2012; 8:719-30. [PubMed: 22647656]

29. Mizushima N, Levine B, Cuervo AM, Klionsky DJ. Autophagy fights disease through cellular selfdigestion. Nature. 2008; 451:1069-75. [PubMed: 18305538]

30. Berg TO, Fengsrud M, Stromhaug PE, Berg T, Seglen PO. Isolation and characterization of rat liver amphisomes. Evidence for fusion of autophagosomes with both early and late endosomes. J. Biol. Chem. 1998; 273:21883-92. [PubMed: 9705327]

31. Samie MA, Xu H. Lysosomal exocytosis and lipid storage disorders. J. Lipid Res. 2014; 55:9951009. [PubMed: 24668941]

32. Reddy A, Caler EV, Andrews NW. Plasma membrane repair is mediated by $\mathrm{Ca}^{2+}$-regulated exocytosis of lysosomes. Cell. 2001; 106:157-69. [PubMed: 11511344]

33. Medina DL, Fraldi A, Bouche V, Annunziata F, Mansueto G, et al. Transcriptional activation of lysosomal exocytosis promotes cellular clearance. Dev. Cell. 2011; 21:421-30. [PubMed: 21889421]

34. Rao SK, Huynh C, Proux-Gillardeaux V, Galli T, Andrews NW. Identification of SNAREs involved in synaptotagmin VII-regulated lysosomal exocytosis. J. Biol. Chem. 2004; 279:2047179. [PubMed: 14993220]

35. Samie M, Wang X, Zhang X, Goschka A, Li X, et al. A TRP channel in the lysosome regulates large particle phagocytosis via focal exocytosis. Dev. Cell. 2013; 26:511-24. [PubMed: 23993788]

36. Sagne C, Gasnier B. Molecular physiology and pathophysiology of lysosomal membrane transporters. J. Inherit. Metab. Dis. 2008; 31:258-66. [PubMed: 18425435]

37. Kalatzis V, Cherqui S, Antignac C, Gasnier B. Cystinosin, the protein defective in cystinosis, is a $\mathrm{H}^{+}$-driven lysosomal cystine transporter. EMBO J. 2001; 20:5940-49. [PubMed: 11689434]

38. Liu B, Du H, Rutkowski R, Gartner A, Wang X. LAAT-1 is the lysosomal lysinearginine transporter that maintains amino acid homeostasis. Science. 2012; 337:351-54. [PubMed: 22822152]

39. Ogmundsdottir MH, Heublein S, Kazi S, Reynolds B, Visvalingam SM, et al. Proton-assisted amino acid transporter PAT1 complexes with Rag GTPases and activates TORC1 on late endosomal and lysosomal membranes. PLOS ONE. 2012; 7:e36616. [PubMed: 22574197]

40. Kiselyov K, Colletti GA, Terwilliger A, Ketchum K, Lyons CW, et al. TRPML: transporters of metals in lysosomes essential for cell survival? Cell Calcium. 2011; 50:288-94. [PubMed: 21621258]

41. Mills E, Dong XP, Wang F, Xu H. Mechanisms of brain iron transport: insight into neurodegeneration and CNS disorders. Future Med. Chem. 2010; 2:51. [PubMed: 20161623]

42. Dong XP, Cheng X, Mills E, Delling M, Wang F, et al. The type IV mucolipidosis-associated protein TRPML1 is an endolysosomal iron release channel. Nature. 2008; 455:992-96. [PubMed: 18794901]

43. Kukic I, Lee JK, Coblentz J, Kelleher SL, Kiselyov K. Zinc-dependent lysosomal enlargement in TRPML1-deficient cells involves MTF-1 transcription factor and ZnT4 (Slc30a4) transporter. Biochem. J. 2013; 451:155-63. [PubMed: 23368743]

44. Eichelsdoerfer JL, Evans JA, Slaugenhaupt SA, Cuajungco MP. Zinc dyshomeostasis is linked with the loss of mucolipidosis IV-associated TRPML1 ion channel. J. Biol. Chem. 2010; 285:34304-8. [PubMed: 20864526]

45. Infante RE, Wang ML, Radhakrishnan A, Kwon HJ, Brown MS, Goldstein JL. NPC2 facilitates bidirectional transfer of cholesterol between NPC1 and lipid bilayers, a step in cholesterol egress from lysosomes. Proc. Natl. Acad. Sci. USA. 2008; 105:15287-92. [PubMed: 18772377] 
46. Lloyd-Evans E, Morgan AJ, He X, Smith DA, Elliot-Smith E, et al. Niemann-Pick disease type C1 is a sphingosine storage disease that causes deregulation of lysosomal calcium. Nat. Med. 2008; 14:1247-55. [PubMed: 18953351]

47. Vitner EB, Platt FM, Futerman AH. Common and uncommon pathogenic cascades in lysosomal storage diseases. J. Biol. Chem. 2010; 285:20423-27. [PubMed: 20430897]

48. Schulze H, Sandhoff K. Lysosomal lipid storage diseases. Cold Spring Harb. Perspect. Biol. 2011; 3:a004804. [PubMed: 21502308]

49. Parkinson-Lawrence EJ, Shandala T, Prodoehl M, Plew R, Borlace GN, Brooks DA. Lysosomal storage disease: revealing lysosomal function and physiology. Physiology. 2010; 25:102-15. [PubMed: 20430954]

50. Mindell JA. Lysosomal acidification mechanisms. Annu. Rev. Physiol. 2012; 74:69-86. [PubMed: 22335796]

51. Walkley SU, Vanier MT. Secondary lipid accumulation in lysosomal disease. Biochim. Biophys. Acta. 2009; 1793:726-36. [PubMed: 19111580]

52. Ballabio A, Gieselmann V. Lysosomal disorders: from storage to cellular damage. Biochim. Biophys. Acta. 2009; 1793:684-96. [PubMed: 19111581]

53. Cang C, Bekele B, Ren D. The voltage-gated sodium channel TPC1 confers endolysosomal excitability. Nat. Chem. Biol. 2014; 10:463-69. [PubMed: 24776928]

54. Cang C, Zhou Y, Navarro B, Seo YJ, Aranda K, et al. mTOR regulates lysosomal ATP-sensitive two-pore $\mathrm{Na}^{+}$channels to adapt to metabolic state. Cell. 2013; 152:778-90. [PubMed: 23394946]

55. Benjamin D, Hall MN. mTORC1: Turning off is just as important as turning on. Cell. 2014; 156:627-28. [PubMed: 24529368]

56. Bar-Peled L, Schweitzer LD, Zoncu R, Sabatini DM. Ragulator is a GEF for the rag GTPases that signal amino acid levels to mTORC1. Cell. 2012; 150:1196-208. [PubMed: 22980980]

57. Christensen KA, Myers JT, Swanson JA. pH-dependent regulation of lysosomal calcium in macrophages. J. Cell Sci. 2002; 115:599-607. [PubMed: 11861766]

58. Dong XP, Wang X, Xu H. TRP channels of intracellular membranes. J. Neurochem. 2010; 113:313-28. [PubMed: 20132470]

59. Pryor PR, Mullock BM, Bright NA, Gray SR, Luzio JP. The role of intraorganellar $\mathrm{Ca}^{2+}$ in late endosome-lysosome heterotypic fusion and in the reformation of lysosomes from hybrid organelles. J. Cell Biol. 2000; 149:1053-62. [PubMed: 10831609]

60. Czibener C, Sherer NM, Becker SM, Pypaert M, Hui E, et al. $\mathrm{Ca}^{2+}$ and synaptotagmin VIIdependent delivery of lysosomal membrane to nascent phagosomes. J. Cell Biol. 2006; 174:9971007. [PubMed: 16982801]

61. Vergarajauregui S, Martina JA, Puertollano R. Identification of the penta-EF-hand protein ALG-2 as a Ca ${ }^{2+}$-dependent interactor of mucolipin-1. J. Biol. Chem. 2009; 284:36357-66. [PubMed: 19864416]

62. Chapman ER. How does synaptotagmin trigger neurotransmitter release? Annu. Rev. Biochem. 2008; 77:615-41.

63. Schissel SL, Keesler GA, Schuchman EH, Williams KJ, Tabas I. The cellular trafficking and zinc dependence of secretory and lysosomal sphingomyelinase, two products of the acid sphingomyelinase gene. J. Biol. Chem. 1998; 273:18250-59. [PubMed: 9660788]

64. Lockwood TD. Lysosomal metal, redox and proton cycles influencing the CysHis cathepsin reaction. Metallomics. 2013; 5:110-24. [PubMed: 23302864]

65. DeFelice LJ, Goswami T. Transporters as channels. Annu. Rev. Physiol. 2007; 69:87-112. [PubMed: 17059369]

66. Saito M, Hanson PI, Schlesinger P. Luminal chloride-dependent activation of endosome calcium channels: patch clamp study of enlarged endosomes. J. Biol. Chem. 2007; 282:27327-33. [PubMed: 17609211]

67. Venugopal B, Browning MF, Curcio-Morelli C, Varro A, Michaud N, et al. Neurologic, gastric, and opthalmologic pathologies in a murine model of mucolipidosis type IV. Am. J. Hum. Genet. 2007; 81:1070-83. [PubMed: 17924347] 
68. Dong XP, Shen D, Wang X, Dawson T, Li X, et al. PI $(3,5) \mathrm{P}_{2}$ controls membrane trafficking by direct activation of mucolipin $\mathrm{Ca}^{2+}$ release channels in the endolysosome. Nat. Commun. 2010; 1:38. [PubMed: 20802798]

71. Harikumar P, Reeves JP. The lysosomal proton pump is electrogenic. J. Biol. Chem. 1983; 258:10403-10. [PubMed: 6224789]

72. Sasaki M, Takagi M, Okamura Y. A voltage sensor-domain protein is a voltage-gated proton channel. Science. 2006; 312:589-92.

73. Ramsey IS, Delling M, Clapham DE. An introduction to TRP channels. Annu. Rev. Physiol. 2006; 68:619-47. [PubMed: 16460286]

74. Graves AR, Curran PK, Smith CL, Mindell JA. The $\mathrm{Cl}^{-} \mathrm{H}^{+}$antiporter ClC-7 is the primary chloride permeation pathway in lysosomes. Nature. 2008; 453:788-92. [PubMed: 18449189]

75. Leisle L, Ludwig CF, Wagner FA, Jentsch TJ, Stauber T. ClC-7 is a slowly voltage-gated $2 \mathrm{Cl}^{-} 1 \mathrm{H}$ ${ }^{+}$-exchanger and requires Ostm1 for transport activity. EMBO J. 2011; 30:2140-52. [PubMed: 21527911]

76. Hodgkin AL. Ionic movements and electrical activity in giant nerve fibres. Proc. R. Soc. B. 1958; 148:1-37. [PubMed: 13494473]

78. Colletti GA, Kiselyov K. Trpml1. Adv. Exp. Med. Biol. 2011; 704:209-19. [PubMed: 21290297]

79. Kiselyov K, Yamaguchi S, Lyons CW, Muallem S. Aberrant $\mathrm{Ca}^{2+}$ handling in lysosomal storage disorders. Cell Calcium. 2010; 47:103-11. [PubMed: 20053447]

80. Schieder M, Rotzer K, Bruggemann A, Biel M, Wahl-Schott C. Planar patch clamp approach to characterize ionic currents from intact lysosomes. Sci. Signal. 2010; 3:p13.

81. Rybalchenko V, Ahuja M, Coblentz J, Churamani D, Patel S, et al. Membrane potential regulates nicotinic acid adenine dinucleotide phosphate (NAADP) dependence of the $\mathrm{pH}-$ and $\mathrm{Ca}^{2+}$ sensitive organellar two-pore channel TPC1. J. Biol. Chem. 2012; 287:20407-16. [PubMed: 22500018]

82. Jha A, Ahuja M, Patel S, Brailoiu E, Muallem S. Convergent regulation of the lysosomal two-pore channel-2 by $\mathrm{Mg}^{2+}$, NAADP, PI(3,5)P 2 and multiple protein kinases. EMBO J. 2014; 33:501-11. [PubMed: 24502975]

83. Cheng X, Shen D, Samie M, Xu H. Mucolipins: intracellular TRPML1-3 channels. FEBS Lett. 2010; 584:2013-21. [PubMed: 20074572]

84. Bargal R, Avidan N, Olender T, Ben Asher E, Zeigler M, et al. Mucolipidosis type IV: novel MCOLN1 mutations in Jewish and non-Jewish patients and the frequency of the disease in the Ashkenazi Jewish population. Hum. Mutat. 2001; 17:397-402. [PubMed: 11317355]

85. Sun M, Goldin E, Stahl S, Falardeau JL, Kennedy JC, et al. Mucolipidosis type IV is caused by mutations in a gene encoding a novel transient receptor potential channel. Hum. Mol. Genet. 2000; 9:2471-78. [PubMed: 11030752]

86. Sardiello M, Palmieri M, di Ronza A, Medina DL, Valenza M, et al. A gene network regulating lysosomal biogenesis and function. Science. 2009; 325:473-77. [PubMed: 19556463]

87. Grimm C, Hassan S, Wahl-Schott C, Biel M. Role of TRPML and two-pore channels in endolysosomal cation homeostasis. J. Pharmacol. Exp. Ther. 2012; 342:236-44. [PubMed: 22518024]

88. Vergarajauregui S, Puertollano R. Two di-leucine motifs regulate trafficking of mucolipin-1 to lysosomes. Traffic. 2006; 7:337-53. [PubMed: 16497227]

89. Pryor PR, Reimann F, Gribble FM, Luzio JP. Mucolipin-1 is a lysosomal membrane protein required for intracellular lactosylceramide traffic. Traffic. 2006; 7:1388-98. [PubMed: 16978393]

90. Abe K, Puertollano R. Role of TRP channels in the regulation of the endosomal pathway. Physiology. 2011; 26:14-22. [PubMed: 21357899]

91. Zhang X, Li X, Xu H. Phosphoinositide isoforms determine compartment-specific ion channel activity. Proc. Natl. Acad. Sci. USA. 2012; 109:11384-89. [PubMed: 22733759]

92. Dong XP, Shen D, Wang X, Dawson T, Li X, et al. PI (3,5) $\mathrm{P}_{2}$ controls membrane traffic by direct activation of mucolipin Ca release channels in the endolysosome. Nat. Commun. 2010; 1:38. [PubMed: 20802798] 
93. Di Paolo G, De Camilli P. Phosphoinositides in cell regulation and membrane dynamics. Nature. 2006; 443:651-57. [PubMed: 17035995]

94. McCartney AJ, Zhang Y, Weisman LS. Phosphatidylinositol 3,5-bisphosphate: low abundance, high significance. BioEssays. 2014; 36:52-64. [PubMed: 24323921]

95. Falkenburger BH, Jensen JB, Dickson EJ, Suh BC, Hille B. Phosphoinositides: lipid regulators of membrane proteins. J. Physiol. 2010; 588:3179-85. [PubMed: 20519312]

96. Li X, Wang X, Zhang X, Zhao M, Tsang WL, et al. Genetically encoded fluorescent probe to visualize intracellular phosphatidylinositol 3,5-bisphosphate localization and dynamics. Proc. Natl. Acad. Sci. USA. 2013; 110:21165-70. [PubMed: 24324172]

97. Grimm C, Jors S, Saldanha SA, Obukhov AG, Pan B, et al. Small molecule activators of TRPML3. Chem. Biol. 2010; 17:135-48. [PubMed: 20189104]

98. Shen D, Wang X, Xu H. Pairing phosphoinositides with calcium ions in endolysosomal dynamics: Phosphoinositides control the direction and specificity of membrane trafficking by regulating the activity of calcium channels in the endolysosomes. BioEssays. 2011; 33:448-57. [PubMed: 21538413]

99. Thompson EG, Schaheen L, Dang H, Fares H. Lysosomal trafficking functions of mucolipin-1 in murine macrophages. BMC Cell Biol. 2007; 8:54. [PubMed: 18154673]

100. Vergarajauregui S, Connelly PS, Daniels MP, Puertollano R. Autophagic dysfunction in mucolipidosis type IV patients. Hum. Mol. Genet. 2008; 17:2723-37. [PubMed: 18550655]

101. Curcio-Morelli C, Charles FA, Micsenyi MC, Cao Y, Venugopal B, et al. Macroautophagy is defective in mucolipin-1-deficient mouse neurons. Neurobiol. Dis. 2010; 40:370-77. [PubMed: 20600908]

102. Wong CO, Li R, Montell C, Venkatachalam K. Drosophila TRPML is required for TORC1 activation. Curr. Biol. 2012; 22:1616-21. [PubMed: 22863314]

103. Chen CS, Bach G, Pagano RE. Abnormal transport along the lysosomal pathway in mucolipidosis, type IV disease. Proc. Natl. Acad. Sci. USA. 1998; 95:6373-78. [PubMed: 9600972]

104. Treusch S, Knuth S, Slaugenhaupt SA, Goldin E, Grant BD, Fares H. Caenorhabditis elegans functional orthologue of human protein h-mucolipin-1 is required for lysosome biogenesis. Proc. Natl. Acad. Sci. USA. 2004; 101:4483-88. [PubMed: 15070744]

105. Dong XP, Wang X, Shen D, Chen S, Liu M, et al. Activating mutations of the TRPML1 channel revealed by proline-scanning mutagenesis. J. Biol. Chem. 2009; 284:32040-52. [PubMed: 19638346]

106. LaPlante JM, Sun M, Falardeau J, Dai D, Brown EM, et al. Lysosomal exocytosis is impaired in mucolipidosis type IV. Mol. Genet. Metab. 2006; 89:339-48. [PubMed: 16914343]

107. Aderem A, Underhill DM. Mechanisms of phagocytosis in macrophages. Annu. Rev. Immunol. 1999; 17:593-623. [PubMed: 10358769]

108. McNeil PL, Kirchhausen T. An emergency response team for membrane repair. Nat. Rev. Mol. Cell Biol. 2005; 6:499-505. [PubMed: 15928713]

108a. Cheng X, Zhang X, Gao Q, Azar M, Tsang WL, et al. An Intracellular Ca2+ Channel is Required For Sarcolemma Repair to Prevent Muscular Dystrophy. Nature Medicine. 2014 in press.

109. Babst M. MVB vesicle formation: ESCRT-dependent, ESCRT-independent and everything in between. Curr. Opin. Cell Biol. 2011; 23:452-57. [PubMed: 21570275]

110. Arredouani A, Evans AM, Ma J, Parrington J, Zhu MX, Galione A. An emerging role for NAADP-mediated $\mathrm{Ca}^{2+}$ signaling in the pancreatic $\beta$-cell. Islets. 2010; 2:323-30. [PubMed: 21099331]

111. Ishibashi K, Suzuki M, Imai M. Molecular cloning of a novel form (two-repeat) protein related to voltage-gated sodium and calcium channels. Biochem. Biophys. Res. Commun. 2000; 270:37076. [PubMed: 10753632]

112. Brailoiu E, Hooper R, Cai X, Brailoiu GC, Keebler MV, et al. An ancestral deuterostome family of two-pore channels mediates nicotinic acid adenine dinucleotide phosphate-dependent calcium release from acidic organelles. J. Biol. Chem. 2010; 285:2897-901. [PubMed: 19940116] 
113. Hedrich R, Marten I. TPC1-SV channels gain shape. Mol. Plant. 2011; 4:428-41. [PubMed: 21459829]

114. Calcraft PJ, Ruas M, Pan Z, Cheng X, Arredouani A, et al. NAADP mobilizes calcium from acidic organelles through two-pore channels. Nature. 2009; 459:596-600.

115. Ren D. Sodium leak channels in neuronal excitability and rhythmic behaviors. Neuron. 2011; 72:899-911. [PubMed: 22196327]

116. Cang C, Zhou Y, Navarro B, Seo Y-J, Aranda K, et al. mTOR regulates lysosomal ATP-sensitive two-pore $\mathrm{Na}^{+}$channels to adapt to metabolic state. Cell. 2013; 152:778-90. [PubMed: 23394946]

117. Murata Y, Iwasaki H, Sasaki M, Inaba K, Okamura Y. Phosphoinositide phosphatase activity coupled to an intrinsic voltage sensor. Nature. 2005; 435:1239-43. [PubMed: 15902207]

118. Boccaccio A, Scholz-Starke J, Hamamoto S, Larisch N, Festa M, et al. The phosphoinositide $\mathrm{PI}(3,5) \mathrm{P}$ mediates activation of mammalian but not plant TPC proteins: functional expression of endolysosomal channels in yeast and plant cells. Cell Mol. Life Sci. 2014 In press; doi: 10.1007s00018-014-1623-2.

119. Bridges D, Ma JT, Park S, Inoki K, Weisman LS, Saltiel AR. Phosphatidylinositol 3,5bisphosphate plays a role in the activation and subcellular localization of mechanistic target of rapamycin 1. Mol. Biol. Cell. 2012; 23:2955-62.

120. Nichols CG. KATP channels as molecular sensors of cellular metabolism. Nature. 2006; 440:470-76. [PubMed: 16554807]

121. Laplante M, Sabatini DM. mTOR signaling in growth control and disease. Cell. 2012; 149:27493.

122. Dennis PB, Jaeschke A, Saitoh M, Fowler B, Kozma SC, Thomas G. Mammalian TOR: a homeostatic ATP sensor. Science. 2001; 294:1102-5. [PubMed: 11691993]

123. Sancak Y, Bar-Peled L, Zoncu R, Markhard AL, Nada S, Sabatini DM. Ragulator-Rag complex targets mTORC1 to the lysosomal surface and is necessary for its activation by amino acids. Cell. 2010; 141:290-303.

124. Pitt SJ, Funnell TM, Sitsapesan M, Venturi E, Rietdorf K, et al. TPC2 is a novel NAADPsensitive $\mathrm{Ca}^{2+}$ release channel, operating as a dual sensor of luminal $\mathrm{pH}$ and $\mathrm{Ca}^{2+} \mathrm{J}$. Biol. Chem. 2010; 285:35039-46. [PubMed: 20720007]

125. Morgan AJ, Galione A. Two-pore channels (TPCs): current controversies. BioEssays. 2014; 36:173-83.

126. Lin-Moshier Y, Walseth TF, Churamani D, Davidson SM, Slama JT, et al. Photoaffinity labeling of nicotinic acid adenine dinucleotide phosphate (NAADP) targets in mammalian cells. J. Biol. Chem. 2012; 287:2296-307. [PubMed: 22117075]

127. Lee MA, Dunn RC, Clapham DE, Stehno-Bittel L. Calcium regulation of nuclear pore permeability. Cell Calcium. 1998; 23:91-101. [PubMed: 9601604]

128. Ichas F, Jouaville LS, Mazat JP. Mitochondria are excitable organelles capable of generating and conveying electrical and calcium signals. Cell. 1997; 89:1145-53. [PubMed: 9215636]

129. Davis LC, Morgan AJ, Chen JL, Snead CM, Bloor-Young D, et al. NAADP activates two-pore channels on T cell cytolytic granules to stimulate exocytosis and killing. Curr. Biol. 2012; 22:2331-37. [PubMed: 23177477]

130. Notomi T, Ezura Y, Noda M. Identification of two-pore channel 2 as a novel regulator of osteoclastogenesis. J. Biol. Chem. 2012; 287:35057-64. [PubMed: 22833668]

131. Bolton, E.; Bayliss, R.; Kalungia, CA.; Bloor-Young, D.; Ruas da Silva, M., et al. The involvement of NAADP and two-pore $\mathrm{Ca}^{2+}$ channels in the cardiac $\beta$-adrenergic response. Presented at Biophys. Soc. Annu. Meet., 58th; Philadelphia. Feb 2-6. 2013

132. Pereira GJ, Hirata H, Fimia GM, do Carmo LG, Bincoletto C, et al. Nicotinic acid adenine dinucleotide phosphate (NAADP) regulates autophagy in cultured astrocytes. J. Biol. Chem. 2011; 286:27875-81. [PubMed: 21610076]

133. Durlu-Kandilci NT, Ruas M, Chuang KT, Brading A, Parrington J, Galione A. TPC2 proteins mediate nicotinic acid adenine dinucleotide phosphate (NAADP)- and agonist-evoked contractions of smooth muscle. J. Biol. Chem. 2010; 285:24925-32. [PubMed: 20547763]

133a. Grimm C, Holdt LM, Chen CC, Hassan S, Muller C, Jörs S, Cuny H, Kissing S, Schröder B, Butz E, Northoff B, Castonguay J, Luber CA, Moser M, Spahn S, Lullmann-Rauch R, Fendel C, 
Klugbauer N, Griesbeck O, Haas A, Mann M, Bracher F, Teupser D, Saftig P, Biel M, WahlSchott C. High susceptibility to fatty liver disease in two-pore channel 2 deficient mice. Nat. Commun. 2014 in press.

134. Arndt L, Castonguay J, Arlt E, Meyer D, Hassan S, et al. NAADP and the two-pore channel protein 1 participate in the acrosome reaction in mammalian spermatozoa. Mol. Biol. Cell. 2014; 25:948-64. [PubMed: 24451262]

135. Sulem P, Gudbjartsson DF, Stacey SN, Helgason A, Rafnar T, et al. Two newly identified genetic determinants of pigmentation in Europeans. Nat. Genet. 2008; 40:835-37.

136. Choi WG, Toyota M, Kim SH, Hilleary R, Gilroy S. Salt stress-induced $\mathrm{Ca}^{2+}$ waves are associated with rapid, long-distance root-to-shoot signaling in plants. Proc. Natl. Acad. Sci. USA. 2014; 111(17):6497-502. [PubMed: 24706854]

137. Bonaventure G, Gfeller A, Proebsting WM, Hortensteiner S, Chetelat A, et al. A gain-of-function allele of TPC1 activates oxylipin biogenesis after leaf wounding in Arabidopsis. Plant J. 2007; 49:889-98. [PubMed: 17253984]

138. Venkatachalam K, Long AA, Elsaesser R, Nikolaeva D, Broadie K, Montell C. Motor deficit in a Drosophila model of mucolipidosis type IV due to defective clearance of apoptotic cells. Cell. 2008; 135:838-51. [PubMed: 19041749]

139. Spampanato C, Feeney E, Li L, Cardone M, Lim JA, et al. Transcription factor EB (TFEB) is a new therapeutic target for Pompe disease. EMBO Mol. Med. 2013; 5:691-706. [PubMed: 23606558]

140. Sardiello M, Ballabio A. Lysosomal enhancement: a CLEAR answer to cellular degradative needs. Cell Cycle. 2009; 8:4021-22. [PubMed: 19949301] 


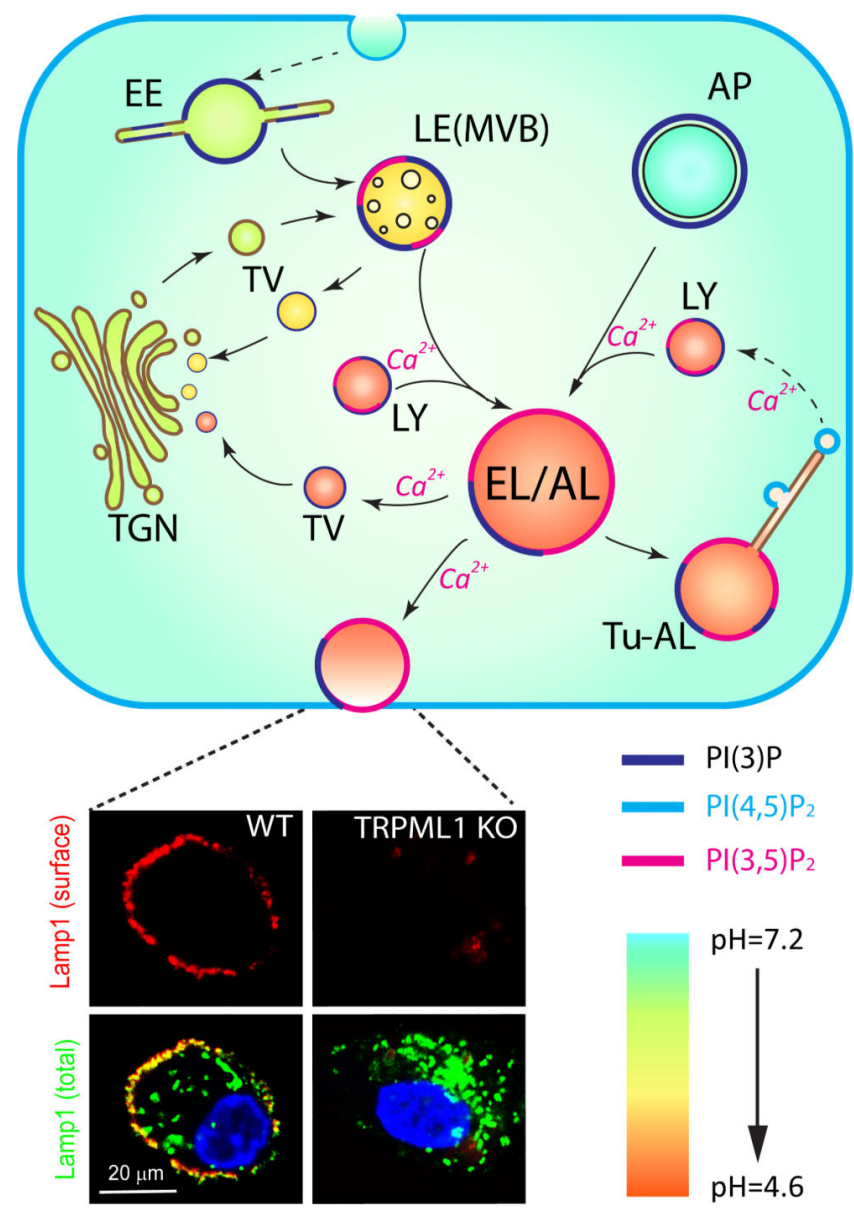

Figure 1.

(Upper panel) Lysosomal export and trafficking pathways. Lysosomes receive inputs from both endocytic and autophagic pathways. Endocytic substrates are delivered first to early endosomes and then to late endosomes (LEs). LEs then fuse with lysosomes to form endolysosome (EL) hybrids. Damaged intracellular organelles enter the autophagic pathway in autophagosomes (APs), which then fuse with lysosomes to form autolysosomes (ALs). Endocytic and autophagic substrates are degraded in ELs and ALs by lysosomal hydrolases. ALs and ELs may exchange materials or fuse directly to form EL-AL hybrids (139). Upon degradation, insoluble catabolites, such as lipids, can be transported to the trans-Golgi network (TGN) for reutilization via transport vesicles (TVs) in the retrograde trafficking pathway or can be released into the extracellular medium via lysosomal exocytosis. Upon completion of lysosomal degradation, ALs undergo extensive tubulation to become tubular ALs (Tu-ALs), from which protolysosomes are regenerated via a fission-based budding-off mechanism. Several trafficking steps are $\mathrm{Ca}^{2+}$ sensitive as indicated $(2,18,25,83)$. The plasma membrane, early endosomes (EEs), LEs, and lysosomes contain compartmentspecific phosphoinositides $\left[\mathrm{PI}(3) \mathrm{P}, \mathrm{PI},(4,5) \mathrm{P}_{2}\right.$, and $\left.\mathrm{PI}(3,5) \mathrm{P}_{2}\right]$ to regulate membrane trafficking and activity of ion channels in a compartment-specific manner. Increased acidification (from $\mathrm{pH} 7.4$ to $\mathrm{pH} 4.6$ ) is associated with endosomal maturation. (Lower panel) Lamp1 (Lysosome-associated membrane protein 1) surface staining allows one to monitor the insertion of lysosomal membrane proteins into the plasma membrane by using a 
monoclonal antibody against a luminal epitope of Lamp1 in non-permeabilized cells.

Mucolipin synthetic agonist 1 (ML-SA1) treatment resulted in the localization of Lamp1 (red) on the plasma membrane in non-permeabilized wild-type, but not trpmll knockout, macrophages. The total amount of Lamp1 (green) proteins was detected by using the same antibody in permeabilized cells. Abbreviations: LY, lysosome MVB, multivesicular body. Lower left panel was modified from Reference 35 with permission. 


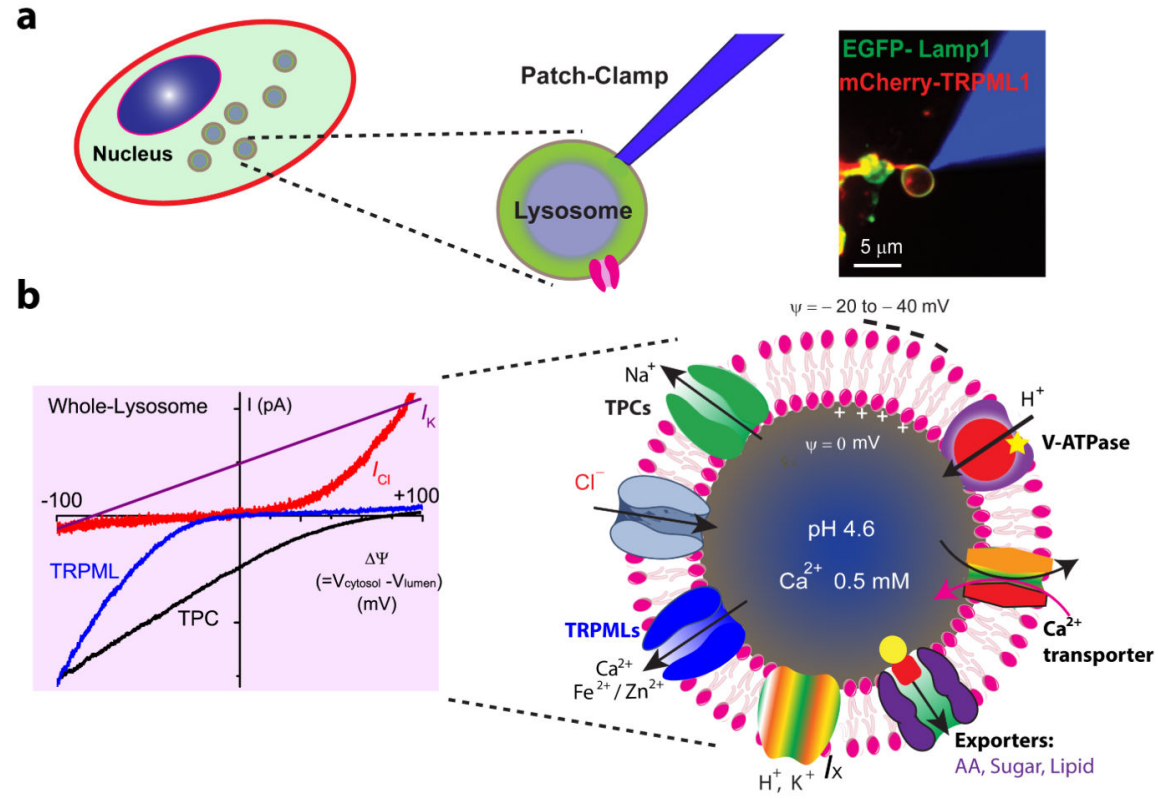

Figure 2.

Ion channels and transporters in the lysosome. (a) An illustration of a whole-lysosome patch-clamp recording $(23,42)$. Right panel was modified from Reference 42 with permission. (b) (Right) [ $\leftarrow^{* *}$ The lysosome is an acidic compartment and with relatively high $\left[\mathrm{Ca}^{2+}\right]$. These gradients are established by V-ATPases and putative $\mathrm{Ca}^{2+}$ transporters. The lysosomal membrane potential $(\Delta \psi)$ is cytosolic-side negative, with $\Delta \psi$ ranging from -20 to $-40 \mathrm{mV}$. The products of lysosomal degradation, such as amino acids (AAs), sugars, and lipids, are transported out of the lysosome via specific exporters. Among the conductances that have been identified, two-pore channels (TPCs) encode $I_{\mathrm{Na}}$, and Mucolipin TRP channels (TRPMLs) encode $I_{\mathrm{Ca}}$ and $I_{\mathrm{Fe}} ; \mathrm{ClC}-7$ is presumed to encode $I_{\mathrm{Cl}}$. Several other conductances, such as $I_{\mathrm{H}}$ and $I_{\mathrm{K}}$, have been electrophysiologically but not molecularly characterized. (Left) $I$ - $\Psi$ curves of four lysosomal channels or currents (TPCs, TRPMLs, $I_{\mathrm{Cl}}$, and $I_{\mathrm{K}}$ ) are shown on the left. 


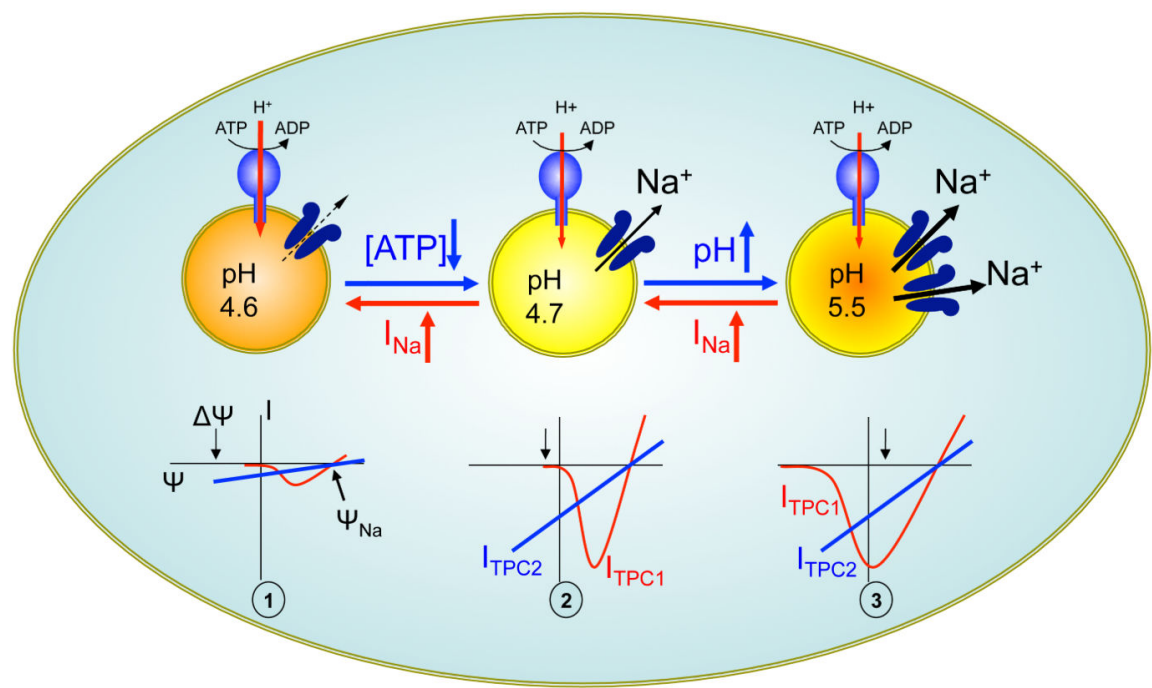

Figure 3.

A model for nutrient sensing by two-pore channels (TPCs). (Stage 1) In nutrient-replete cells, TPCs are minimally open at resting lysosomal membrane potential $(\Delta \psi)$. (Stage 2$)$ Upon a drop in [ATP], TPC2 opens to promote $\mathrm{Na}^{+}$efflux (into the cytosol) and to depolarize the membrane (lumen becomes less positive). In TPC1-expressing organelles, a $\Delta \Psi$ above TPC1's activation threshold also triggers TPC1 opening. (Stage 3) Following lysosomal alkalinization, TPC1 lowers its activation threshold. Membrane depolarization and $\mathrm{Na}^{+}$efflux potentiate $\mathrm{H}^{+}$pumping by the V-ATPase and help stabilize $\mathrm{pH}$. Strong positive feedback between $\Delta \psi$ and TPC1 can also lead to plateau potentials and membrane bistability. $\Psi_{\mathrm{Na}}$ denotes $\mathrm{Na}^{+}$Nernst potential. See References 53 and 54 for details. 